\title{
A Comparative Safety Analysis of Medicines Based on the UK Pharmacovigilance and General Practice Prescribing Data in England
}

\author{
KINAN MOKBEL, ROB DANIELS, MICHAEL N. WEEDON and LEIGH JACKSON \\ College of Medicine and Health, University of Exeter Medical School, Exeter, U.K.
}

\begin{abstract}
Background/Aim: Adverse drug reactions (ADRs) represent a major concern leading to significant increases in both morbidity and mortality globally. Providing healthcare professionals (HCPs) and patients with real-world data on drug safety is imperative to facilitate informed decisionmaking. The study aimed to determine the feasibility of creating comparative safety charts for medicines by mapping $A D R$ reporting onto prescribing data. Materials and Methods: Data on serious and fatal ADR reports from the Yellow Card database was mapped onto general practice prescription data in England. The rate of serious and fatal ADR reports per million items prescribed was calculated for commonlyprescribed medicines. Results: Quantitative comparative analyses for 137 medicines belonging to 26 therapeutic classes were conducted. Significant differences were observed within most therapeutic classes for the rate of serious and fatal ADR reports per prescribing unit. Conclusion: Despite the limitations of $A D R$ reporting and prescribing databases, the study provides a proof-of-concept for the feasibility of mapping ADR reporting onto prescribing data to create comparative safety charts that could support evidence-based decision-making around formulary choices.
\end{abstract}

All medicines can cause adverse drug reactions (ADRs) leading to increases in both mortality and morbidity and incurring substantial financial costs and a significant burden on healthcare systems worldwide (1-8). The reported prevalence

This article is freely accessible online.

Correspondence to: Kinan Mokbel, University of Exeter Medical School, RILD Building, Royal Devon and Exeter Hospital Wonford, Barrack Road, Exeter, EX2 5DW, U.K. Tel: +44 01392408223, e-mail:k.mokbel@exeter.ac.uk

Key Words: Drug safety, adverse drug reactions, side effects, pharmacovigilance, spontaneous reporting, yellow card scheme, primary care, shared decision-making, general practice, data linkage. of ADRs in primary care is $8.3 \%$, one fifth of which are preventable (9). Serious ADRs may be life-threatening, resulting in death or hospitalisation and may cause permanent disability or congenital abnormalities (birth defects) (10). These serious ADRs account for up to $30 \%$ of all ADRs with many being identified post-marketing (11-13). It has been shown that $30-70 \%$ of ADRs resulting in hospitalisation are considered predictable and thereby potentially preventable $(11,14-17)$.

The detection and quantification of ADRs is a key component of clinical trials prior to approval. While clinical trials are considered the bedrock for assessing drug efficacy, they are less efficient in detecting ADRs, therefore, findings from clinical trials have limited use in extrapolating risks to clinical practice (18-25). Unlike easily-detectable and wellrecognised ADRs that are often identified during pre-marketing in clinical trials, rare and late-onset ADRs remain underdetected until the post-marketing stage, during which medicines are used by a more diverse and larger population than initially intended, and for a longer period in normal clinical practice (2630). Such ADRs are often undetected during clinical trials due to the relatively small number of participants studied (30-33) and the exclusion criteria, which do not usually allow for the frailest patients to participate (34). The limited trial duration and the focus on main outcomes can also hamper the detection of unpredictable (35-37) and relatively-infrequent events (38) that are rarely considered as primary focus and, therefore, may not be accurately diagnosed or reported.

The main method of post-marketing safety surveillance is spontaneous reporting of ADRs (i.e., pharmacovigilance), which remains the cornerstone of safety signal detection systems $(39,40)$ as the majority of new medicine-related safety signals are prompted through this path $(29,41)$. The wellestablished gateway for reporting ADRs in the UK to the Medicines and Healthcare Regulatory Agency (MHRA) is the Yellow Card Scheme (YCS) (42), through which reports of suspected ADRs are submitted on a voluntary basis by both HCPs and patients (43). Nonetheless, pharmaceutical companies have a legal obligation to submit ADRs reports of their products independently. 
While pharmacovigilance databases can be used for hypothesis-free data mining of safety reports (44), their use in pharmaco-epidemiological analyses is limited, mainly due to lack of evidence-based approaches or insufficient accessibility to such data. Hence, performing a retrospective analysis of ADR reports that are available in pharmacovigilance databases can be useful (45-47). However, without adjusting for factors, such as the length of time the medicine has been on the market and the number of people taking it, numerical comparisons and definitive conclusions about the risks of medications made solely on ADR reports can be misleading $(48,49)$. Therefore, to avoid drawing erroneous conclusions, the number of ADR reports should not be used in isolation to determine the incidence of ADRs. Database linkage between data sourced from pharmacovigilance databases and observational data, including prescribing data is desirable $(50,51)$, so as to help eliminate the shortcomings of separate databases (52). Significant results have been published from such linkage studies (53). Mapping medicine usage data onto outcomes data has the potential to quantify the relative risk that is associated with the different medicines (54).

To determine the feasibility of creating quantitative comparative safety charts by mapping 'exposure' data of the items prescribed onto an 'outcome' data of ADR reports, we performed this pilot investigation, linking serious and fatal ADR reports in YCS to the number of prescriptions in general practice in England. While the 'outcome' data is the number of ADR reports recorded, the difference in the number of items prescribed over the period of (Jan-2016 Jan-2021) will be accounted for with the 'exposure' data. This linkage study provides simple and up-to-date quantitative comparative safety charts for medicines belonging to the same therapeutic class in a convenient format. Medicines within a particular therapeutic class are often used for the same indication. This makes comparative figures for medicines within the same therapeutic class of paramount relevance to prescribers seeking to assist patients in making informed decisions about their care. The comparative data generated from this project may also help commissioners make evidence-based decisions on formulary choices.

\section{Materials and Methods}

ADR reporting data. All UK fatal and serious ADR reports received by the MHRA were manually retrieved for all listed medicines from January 2016 until January 2021 from the Interactive Drug Analysis Profiles (iDAPs) in the MHRA's Yellow Card database (42). The data was extracted into Microsoft Excel Spreadsheet (55). To simplify the presentation of the results, both serious and fatal ADR reports were combined. Since MHRA continuously screens for duplicate reports at the stage of data entry, systematic de-duplication was not conducted before analysis.
Prescription data. General practice prescribing data was retrieved from the "OpenPrescribing" interface (56). This covers prescriptions that are written in England by General Practitioners (GPs) and nonmedical prescribers who are linked to GP practices and that are dispensed in the community in the UK. A prescription item refers to a single supply of a medicine written in one prescription form. Prescribing data were manually extracted for each medicine listed and the number of items prescribed for the period from January 2016 to January 2021 was calculated.

Linking ADR reporting data to prescribing data. All medicines available in the MHRA's Yellow Card database were mapped onto prescribing data using the strategy described below.

For medicines with ADR reports falling within the desired period (Jan-2016 to Jan-2021), the number of serious and fatal ADR reports was calculated when prescribing data were available for this period. If prescribing data existed for a particular timeframe where no ADR reports were available, no ADR reports were assumed to have been submitted during this period, counting them as zero. Related prescription data were simultaneously evaluated and the number of items prescribed for the longest period during (Jan2016_Jan-2021) were also calculated. Medicines with ADR reports but without prescription data during this period were excluded.

Since the number of ADR reports in iDAPs for a multiple constituent medicine represents the total number of reports submitted for its both single and combination formulations (e.g., Co-Tenidone containing Atenolol and Chlortalidone), we included ADR reports and prescriptions only for single constituent medicines as the inclusion of such combination products in the denominator (prescribing data) might slightly reduce the apparent ADR rate.

As the ADR reports in iDAPs for a particular medicine may include reports that originate from secondary care along with the reports from general practice (e.g., Furosemide is available in both oral and intravenous formulations), we excluded ADR reports that are likely to have originated from the use of medicines via routes considered inappropriate for general practice (e.g., intravenous formulation).

Medicines were thereafter manually grouped to the therapeutic classifications defined by the British National Formulary (BNF). Medicines that, following classification, fit in more than one category, were "re-classified" based on their prescribing frequency. Clinical judgement was exercised for medicines that could not be unequivocally classified based on the experience of both the prescribing and the clinical practice, for which two clinical researchers were involved. The scope of analyses was then narrowed by including only the most frequently prescribed medicines during the period of interest. Figure 1 illustrates the methodology employed and the exclusion criteria.

Safety profiles for the included medicines were then analysed as per the total number of serious and fatal ADR reports per million items prescribed. Medicines within their therapeutic classes were compared to one another and their relative safety was determined. The concept of 'high-risk medicines' can be used instead of 'high-alert medications' (57). Collectively, we ensured that the most frequently prescribed therapeutic classes in general practice were mapped.

Statistical analyses. The statistical analyses were performed using the software R package (v 4.1.1) 'meta' (58). As the outcomes of the study are rate data that often follow a Poisson distribution, a random intercept Poisson regression model (59) was fitted using the metarate function with the argument "GLMM"(generalised linear mixed-effects model), as previously described (60), to meta-analyse the single rates 


\section{Linkage of ADR Reporting Data onto General Practice Prescription Data}

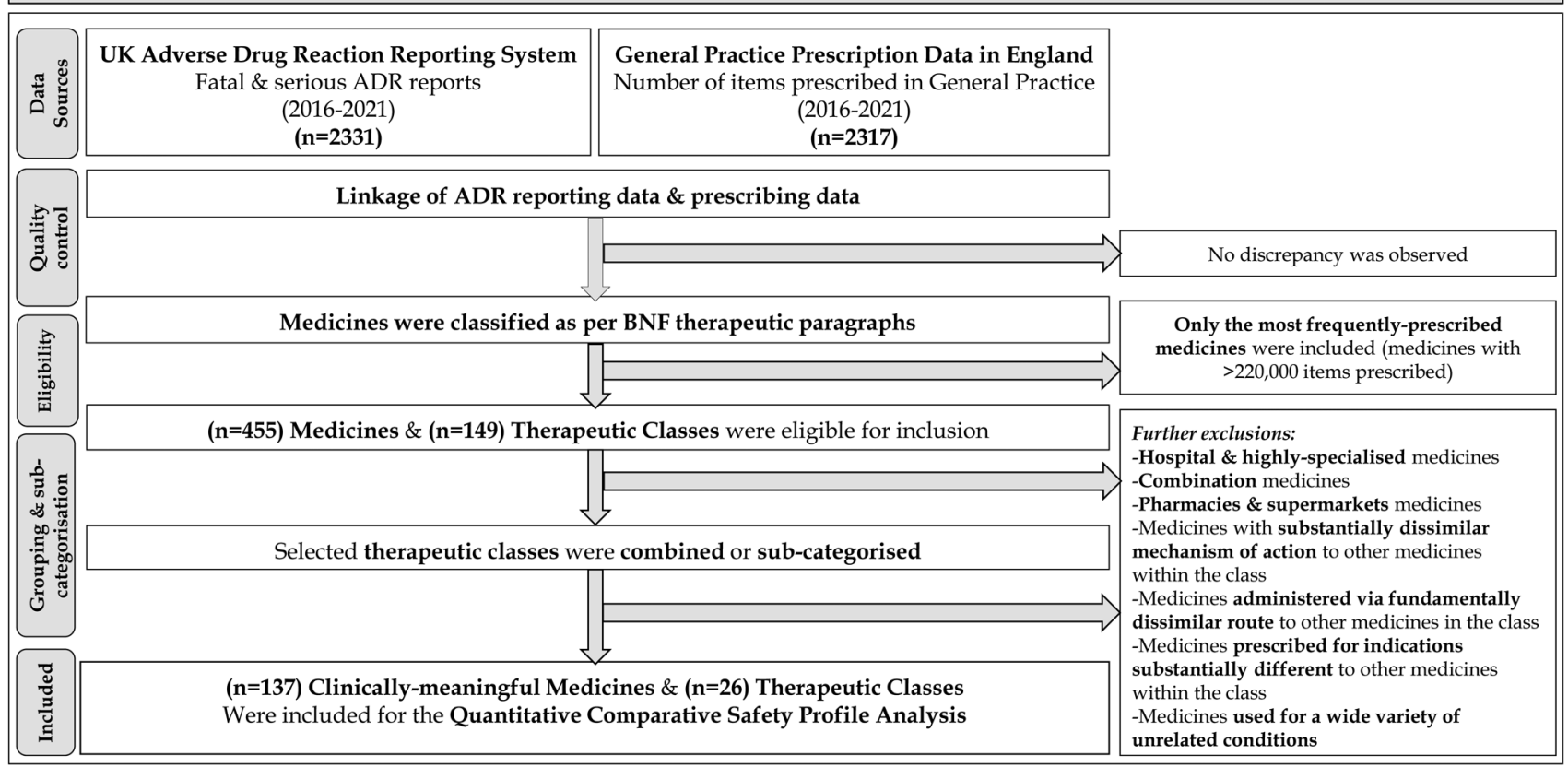

Figure 1. Study methodology data on serious and fatal ADR reports from the MHRA's Yellow Card database was mapped onto general practice prescription data in England extracted from OpenPrescribing platform for the period January 2016 until January 2021. ADR: Adverse drug reactions; MHRA: Medicines and Healthcare Regulatory Agency.

of serious and fatal ADR reports per prescribing unit over the period of interest for the medicines analysed. This approach takes account of the different number prescriptions issued for each medicine over this period. The inclusion of the 'exposure' data of the items prescribed to adjust counts on the 'outcome' data of the ADR reports makes use of the correct probability distributions and, thus, the relative ranking of medicines. Heterogeneity among medicines was evaluated using the $I^{2}$ statistic (61), which represents the percentage of total variance across the medicines within a therapeutic class that is explained by between-medicine heterogeneity (based on $Q$ ) in terms of the rate of serious and fatal ADR reports per prescribing unit (62). Maximumlikelihood estimator (63) was used for the GLMM to calculate the between-medicines variance $\tau^{\wedge} 2$. Forest plots were generated using the same software R package 'meta' to visually summarise the comparative safety profiles for all the medicines included. In the forest plots, we reported $I^{2}, \tau^{\wedge} 2$ and $p$-value for the $Q$-statistic.

Ethical approval. This is an observational study. The Yellow Card and general practice prescribing databases are non-identifiable and anonymised databases. Institutional review board approval was obtained from the ethics committee of the Medical School of Exeter University (reference 21/01/006).

\section{Results}

A total of $(n=2,331)$ medicinal products were identified from the iDAPs. A total of 2,317 chemicals belonging to 406 different therapeutic classes, were identified through the
OpenPrescribing platform. Having mapped all medicines and narrowed the scope of analyses by including only the most frequently-prescribed medicines during the period January 2016 to January 2021, there were 455 frequently-prescribed medicines belonging to 149 therapeutic classes as per the BNF and with $>220,000$ items prescribed during this time. After applying other exclusion criteria, the final analysis dataset included 137 medicines belonging to 26 clinicallymeaningful therapeutic classes.

Based on the $I^{2}$ statistic and the $p$-value for $Q$-statistic, the linkage showed significant differences in terms of the rate of serious and fatal ADR reports per million items prescribed among medicines in 23 classes out of the 26 therapeutic classes analysed $(p<0.05)$, supporting the use of random-effects model. There were only three classes that showed no significant differences among the medicines analysed, namely: i) angiotensin-converting-enzyme inhibitors, ii) potassiumsparing diuretics and aldosterone antagonists, and iii) drugs for erectile dysfunction. Forest plots summarise the safety profiles for all the medicines included (Figure 2, Figure 3, Figure 4, Figure 5, Figure 6, Figure 7 and Figure 8). Forest plots have the potential to enable informed prescribing decisions by allowing any two medicines within a therapeutic class to be compared directly, by considering whether the confidence intervals overlap. For example, in the lipid-lowering drugs, the 


\section{A}

\section{Drug}

Rosuvastatin

Ezetimibe

Fluvastatin

Pravastatin

Atorvastatin

Simvastatin

Fixed effect model

Random effects model

$l^{2}=98 \%, \tau^{2}=0.1498, p=4.17 \times 10^{-51}$

\section{Lipid-regulating drugs}

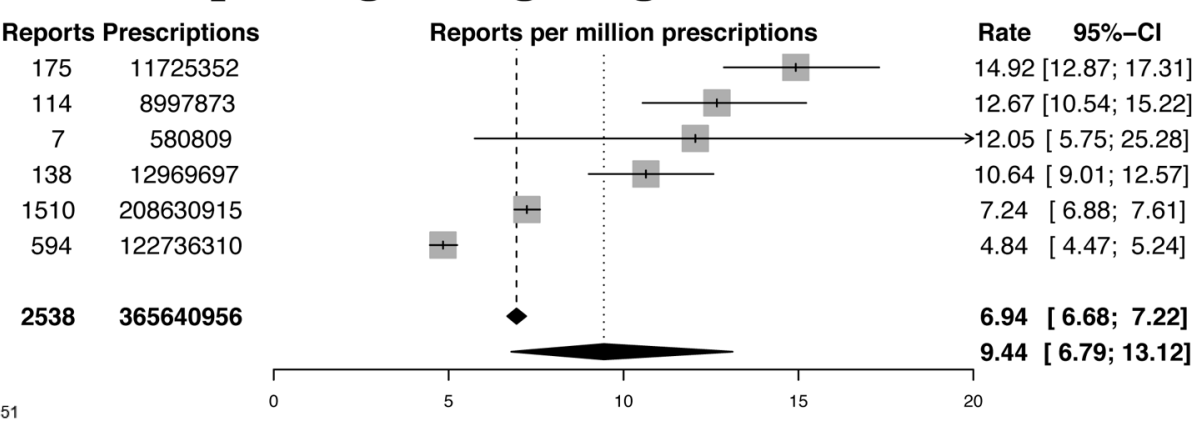

\section{Oral Anticoagulants}

Drug

Edoxaban

Dabigatran

Rivaroxaban

Apixaban

Warfarin

Fixed effect model

Random effects model

$l^{2}=100 \%, \tau^{2}=0.5462, p<5 \times 10^{-100}$

$\begin{array}{cc}\text { Reports } & \text { Prescriptions } \\ 615 & 2804174 \\ 400 & 2251342 \\ 3036 & 18794693 \\ 2961 & 22594184 \\ 1142 & 40877105 \\ & \\ \mathbf{8 1 5 4} & \mathbf{8 7 3 2 1 4 9 8}\end{array}$

Reports per million prescriptions

Rate $95 \%-\mathrm{Cl}$

219.32 [202.65; 237.35]

177.67 [161.09; 195.97]

$161.53[155.89 ; 167.38]$

131.05 [126.42; 135.86]

27.94 [26.36; 29.61]

93.38 [ 91.37; 95.43]

118.07 [ $61.73 ; 225.82]$
C

Drug

Ticagrelor

Prasugrel

Dipyridamole

Clopidogrel

Aspirin

Fixed effect model

Random effects model

$R^{2}=100 \%, \tau^{2}=0.8371, p<5 \times 10^{-100}$

\section{Antiplatelet Drugs}

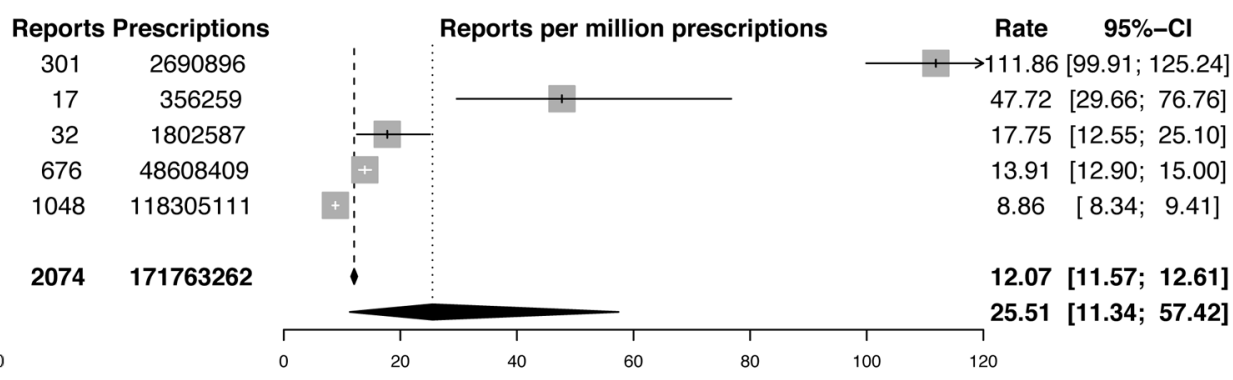

D

Drug

Captopril

Trandolapril

Enalapril

Ramipril

Lisinopril

Perindopril

Fixed effect model Random effects model

$l^{2}=25 \%, \tau^{2}=0, p=2.45 \times 10^{-1}$

\section{Renin-Angiotensin Drugs (ACEIs)}

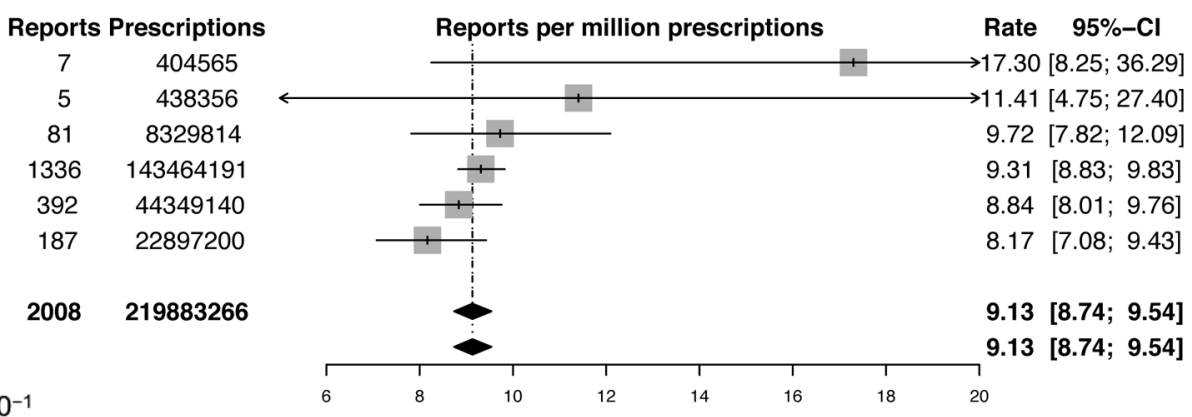

Figure 2. Continued 
$\mathbf{E}$

Drug
Valsartan
Olmesartan
Telmisartan
Irbesartan
Candesartan
Losartan
Eprosartan
Fixed effect model
Random effects model
$l^{2}=100 \%, \tau^{2}=1.6449, p<5 \times 10^{-100}$

$\mathbf{F}$

Drug

Labetalol

Sotalol

Metoprolol

Propranolol

Nebivolol

Carvedilol

Bisoprolol

Atenolol

Fixed effect model

Random effects model

$l^{2}=99 \%, \tau^{2}=0.6821, p=9.98 \times 10^{-121}$

\section{Renin-Angiotensin Drugs (ARBs)}

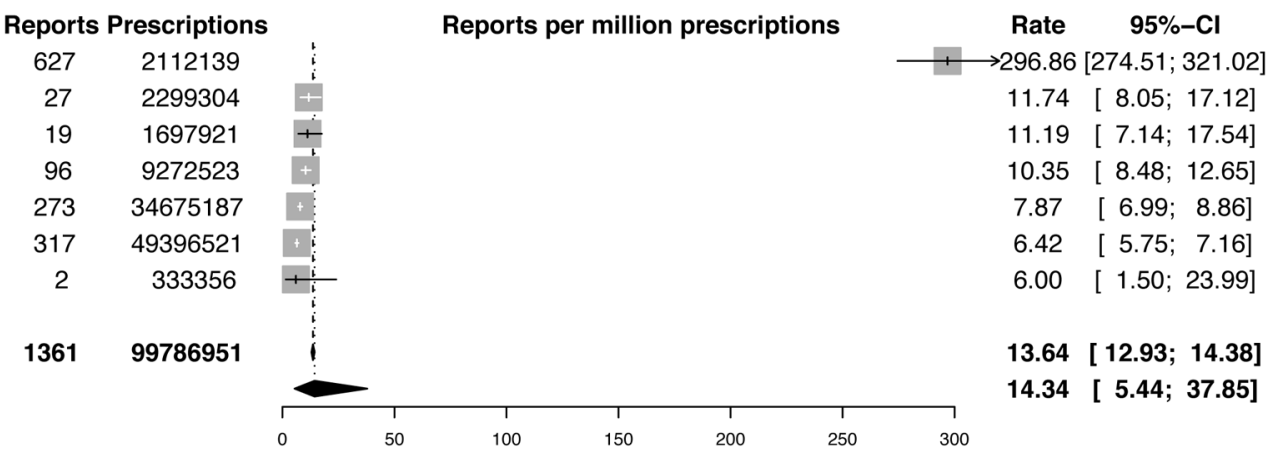

\section{Beta-adrenergic Blockers}

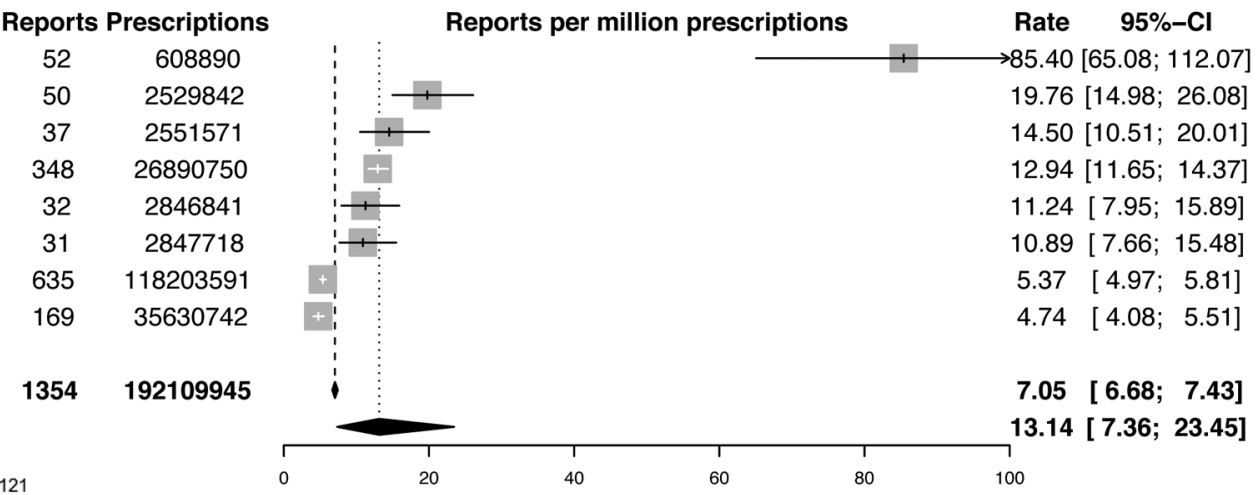

G

\section{Drug}

Nifedipine

Lercanidipine

Amlodipine

Lacidipine

Felodipine

Fixed effect model

Random effects model

$l^{2}=93 \%, \tau^{2}=0.0662, p=4.61 \times 10^{-12}$

\section{Calcium Channel Blockers (Dihydropyridines)}

$\begin{array}{cc}\text { Reports } & \text { Prescriptions } \\ 150 & 8823497 \\ 126 & 12632179 \\ 1321 & 146365206 \\ 25 & 2852708 \\ 151 & 18823258 \\ & \\ 1773 & \mathbf{1 8 9 4 9 6 8 4 8}\end{array}$

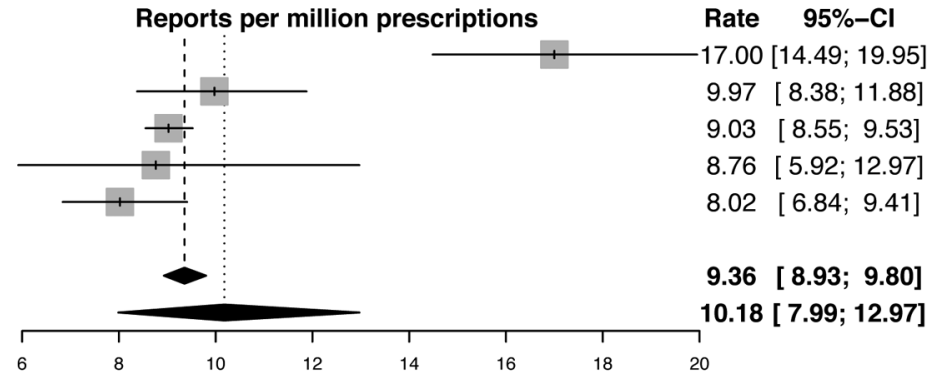

\section{H Calcium Channel Blockers (Non-dihydropyridines)}

Drug

Verapamil

Diltiazem

Fixed effect model

Random effects model

$l^{2}=96 \%, \tau^{2}=0.0958, p=7.19 \times 10^{-7}$

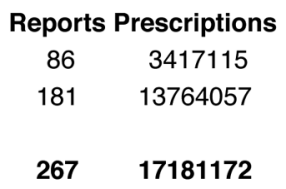

s

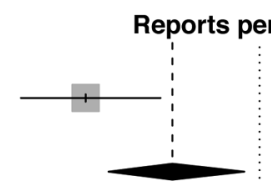

Rate $95 \%-\mathrm{Cl}$

25.17 [20.37; 31.09]

$13.15[11.37 ; 15.21]$

15.54 [13.78; 17.52]

17.94 [11.46; 28.09]

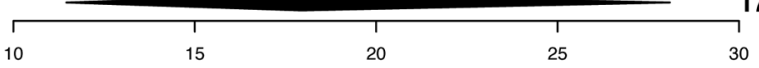




\section{Potassium-sparing Diuretics and Aldosterone Antagonists}

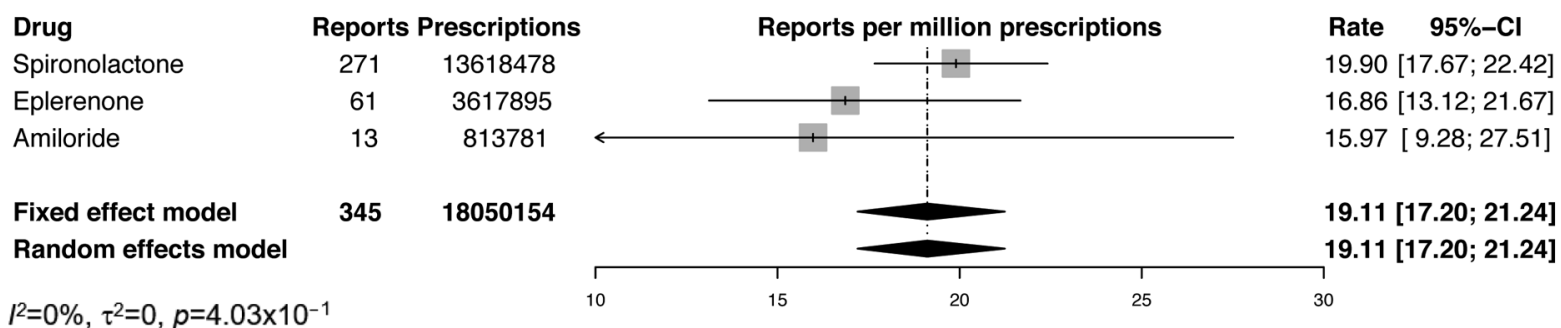

\section{Thiazides and Related Diuretics}

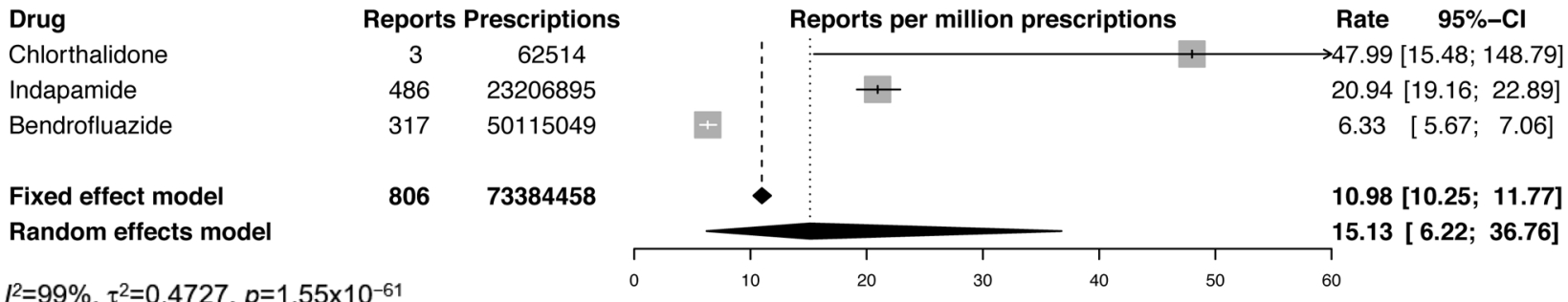

K

Drug

Bumetanide

Furosemide

Fixed effect model

Random effects model

$l^{2}=98 \%, \tau^{2}=0.1195, p=3.23 \times 10^{-13}$

$\begin{array}{cc}\text { Reports } & \text { Prescriptions } \\ 136 & 8326836 \\ 480 & 59633627 \\ & \\ 616 & \mathbf{6 7 9 6 0 4 6 3}\end{array}$

Loop Diuretics

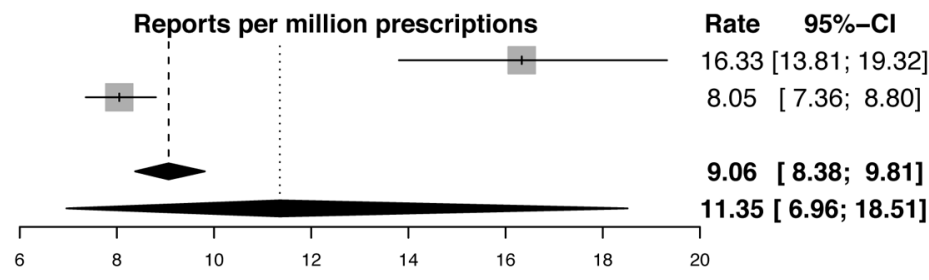

Figure 2. Cardiovascular system. A) Lipid-regulating drugs, B) Oral anticoagulants, C) Antiplatelet drugs, D) Angiotensin-converting enzyme inhibitors (ACEIS), E) Renin-angiotensin receptor blockers (ARBs), F) Beta-adrenergic Blockers, G) Calcium channel blockers (Dihydropyridines), H) Calcium channel blockers (Non-dihydropyridines), I) Potassium-sparing diuretics and aldosterone antagonists, J) Thiazides and Related Diuretics, K) Loop Diuretics.

overlapping confidence intervals for Pravastatin and Fluvastatin show that the rates of ADR reports do not significantly differ. In contrast, the confidence intervals for Atorvastatin and Simvastatin do not overlap, thus, demonstrating that Atorvastatin has a significantly higher rate of serious and fatal ADR reports per prescribing unit compared to Simvastatin.

An additional analysis of the time-trends of the number of ADR reports for some commonly prescribed medicines in general practice indicated that older medicines tend to be under-reported as their safety profiles become well-known and predictable (Figure 9).

A separate analysis of the total ADR reports in both the UK's Yellow Card database from inception until September 2020 and the European pharmacovigilance database, known as 'EudraVigilance' from inception until November 2020, was performed. This analysis showed that $72 \%$ of all ADR reports in the Yellow Card database and $85 \%$ of all ADR reports in EudraVigilance are serious and fatal (Figure 10).

\section{Discussion}

The importance of safe and effective prescribing is stressed by both the UK General Medical Council (64) and the General Pharmaceutical Council (65). Access to accurate data on drug safety is crucial for shared decision making in prescriber-patient consultations. Despite this, there are often many similar drug choices for each indication with only a few tools to objectively compare the safety profiles 
between different medications. The aim of this study was to determine the feasibility of creating quantitative comparative safety charts for medicines belonging to the same therapeutic class. This was achieved by mapping MHRA's ADRs reporting database onto the NHS England general practice prescribing database. This pilot study successfully generated drug safety ratios for serious and fatal ADR reports of common general practice medicines per million items prescribed.

A previous report analysed ADR reports and prescriptions issued in the UK primary care setting between 2008-2012 (66). However, that report investigated the overall number of prescriptions rather than those of individual medicines and was mainly focused on comparing the proportion of ADRs reported for specific age groups with what is expected from the proportion of primary care prescriptions within each of these groups. The study was also limited by the use of IMS Disease Analyzer to estimate the prescriptions issued in the UK primary care. The IMS Disease Analyzer represents only around $1.7 \%$ of the UK general population, and all prescribing figures used there, are, therefore, projected up to estimate the number of prescriptions that reflects the total population of the UK.

Numerous studies and multiple organisations have attempted to identify high-risk medicines (67-71). However, these individual lists of high-risk medicines differ significantly from those in our study as many of them were created with particular focus on medication error reports rather than ADRs (68). Of note, these lists of high-risk medicines were mainly created based on in-patient settings or for particular clinical settings (e.g., acute, ambulatory or long-term care) $(70,72,73)$ and, thereby, may differ substantially for different settings (74).

Other tools have been created to identify high-risk medications including Medication Appropriateness Index (MAI) $(75,76)$, Inappropriate Prescribing in the Elderly Tool (IPET) (77), Screening Tool Alert Doctors to Right Treatment (START) (78), Screening Tool of Older Persons' Prescriptions (STOPP) (79), GerontoNet (80) and Beers criteria. However, these tools were mainly constructed to identify potentially inappropriate medicines (81) and none has the potential to provide clinicians with comparative data for serious ADRs within a therapeutic class. Moreover, most of these tools were developed with a focus on the elderly and in-patient settings, such as including IPET $>70$ years old patients in hospital, and STOPP and Beers criteria ( $>65$ years old patients) $(82,83)$. Consequently, most of these tools may not be generalisable to routine clinical practice across different age groups and populations. Furthermore, tools such as STOPP/START tool were primarily created to formalise the process of conducting a medication review (84) from the consensus of experts rather than based on real-time ADR reports (85). There is no robust evidence as yet that these tools can help reduce the incidence of hospitalisations or deaths (86). Other studies investigating medicines most commonly implicated in ADRs and medication errors, have identified similar medicines and therapeutic classes to IPET, STOPP lists and Beers criteria (87-90).

One systematic literature review has attempted to identify medicines involved in serious and fatal medication events (69), but it was focused on medication errors rather than ADRs identified in normal practice within the license for that medicine. A more recent systematic review investigated ADRs in primary care (9), however, its main objectives were to investigate the prevalence and proportion of preventable ADRs rather than identifying high-risk medicines. Although the review identified therapeutic classes most frequently involved in ADRs in primary care, the classes were involved in all types of ADRs rather than the serious ones. Another review of 100 deaths caused by or related to medicines has identified high risk therapeutic classes of drugs (91), however, it has not specified individual medicines or quantified usage as a denominator. These studies are also prone to a publication bias, as serious events are more frequently reported and published in case reports compared to non-serious ones.

Although this data integration study is sufficient to draw robust preliminary conclusions, the comparative charts should be interpreted with caution taking into account the linkage issues and inherent limitations that largely reflect the nature of the ADR reporting and prescribing data used. However, although the study databases have flaws and limitations, they reflect real world data rather than the product of a controlled clinical trial from which findings have limited use in extrapolating risks to normal clinical practice, particularly for late-onset and rare ADRs.

Linkage issues. Although this study demonstrates that linkage of ADR reporting data to prescribing data is feasible, this is not expected to be complete. First, linkage at the individual patient level was not possible as neither pharmacovigilance nor prescribing databases contain unique patient identifiers. This prevented the detailed investigation of circumstances around individual ADRs.

The second linkage issue is that low volume medicines, based on their prescribing frequency, were excluded so as to reduce the dataset size to a manageable level for this pilot project. This might have under-represented some less frequently prescribed yet clinically important general practice medicines that may still have significant ADRs rates. Finally, although we excluded ADR reports related to medicinal forms deemed inappropriate for general practice (e.g., intravenous formulation), we were unable to completely differentiate between ADR reports originated from general practice and secondary care for formulations considered to be appropriate for prescribing in both settings 


\section{A Antidiabetic Drugs (Biguanides, Sulfonylureas \& Thiazolidinediones)}

Drug
Pioglitazone
Glipizide
Metformin
Glimepiride
Gliclazide
Fixed effect model
Random effects model
$I^{2}=99 \%, \tau^{2}=0.641, p=1.1 \times 10^{-67}$

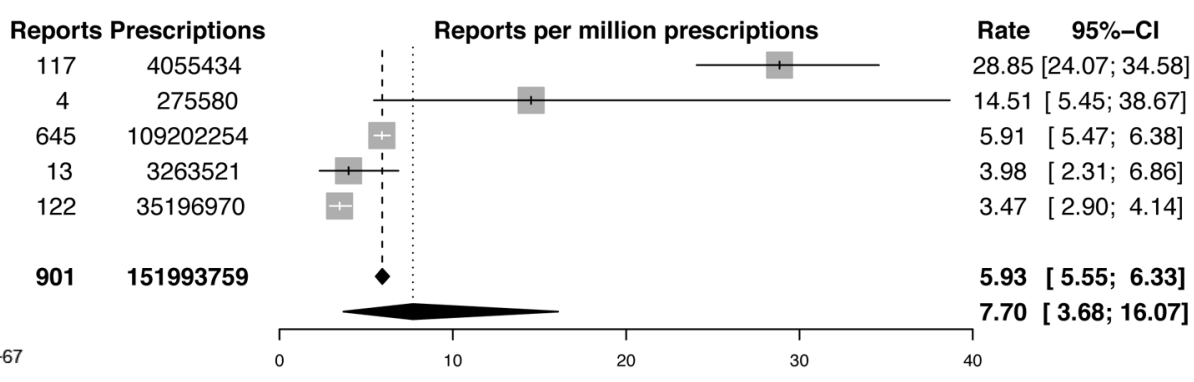

B

$\begin{array}{lrc}\text { Drug } & \text { Reports } & \text { Prescriptions } \\ \text { Semaglutide } & 159 & 439805 \\ \text { Dulaglutide } & 337 & 1866229 \\ \text { Exenatide } & 72 & 773496 \\ \text { Liraglutide } & 202 & 2443901 \\ \text { Lixisenatide } & 22 & 292732 \\ & & \\ \text { Fixed effect model } & 792 & \mathbf{5 8 1 6 1 6 3} \\ \text { Random effects model } & & \\ P^{2}=98 \%, \tau^{2}=0.3469, p=5 \times 10^{-49} & \end{array}$

\section{Antidiabetic Drugs (GLP-1 agonists)}

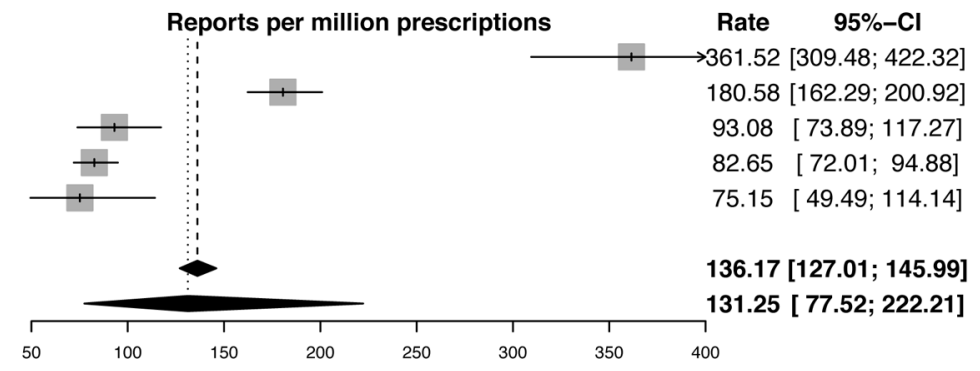

C

Drug

Alogliptin

Linagliptin

Saxagliptin

Vildagliptin

Sitagliptin

Fixed effect model

Random effects model

$l^{2}=91 \%, \tau^{2}=0.0568, p=1.02 \times 10^{-8}$

\section{Antidiabetic Drugs (DPP-4 inhibitors)}

$\begin{array}{cc}\text { Reports } & \text { Prescriptions } \\ 164 & 4996340 \\ 229 & 9140678 \\ 25 & 1266721 \\ 5 & 290549 \\ 210 & 12403449 \\ & \\ \mathbf{6 3 3} & \mathbf{2 8 0 9 7 7 3 7}\end{array}$

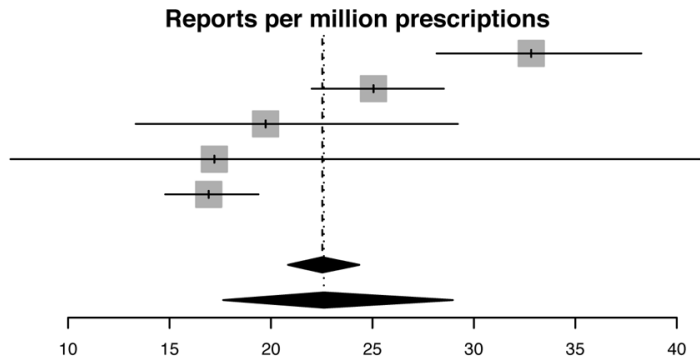

Rate $\quad 95 \%-\mathrm{Cl}$

32.82 [28.17; 38.25]

25.05 [22.01; 28.52]

19.74 [13.34; 29.21]

-17.21 [ $7.16 ; 41.34]$

$16.93[14.79 ; 19.38]$

22.53 [20.84; 24.35]

22.61 [17.65; 28.96]
D

\section{Drug \\ Canagliflozin \\ Empagliflozin \\ Dapagliflozin}

Fixed effect model

Random effects model

$l^{2}=91 \%, \tau^{2}=0.0098, p=1.13 \times 10^{-5}$

\section{Antidiabetic Drugs (SGLT-2 inhibitors)}

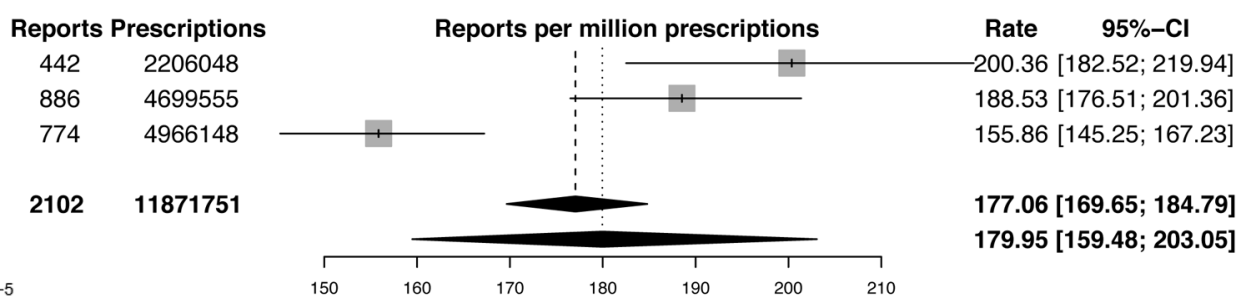

Figure 3. Continued 


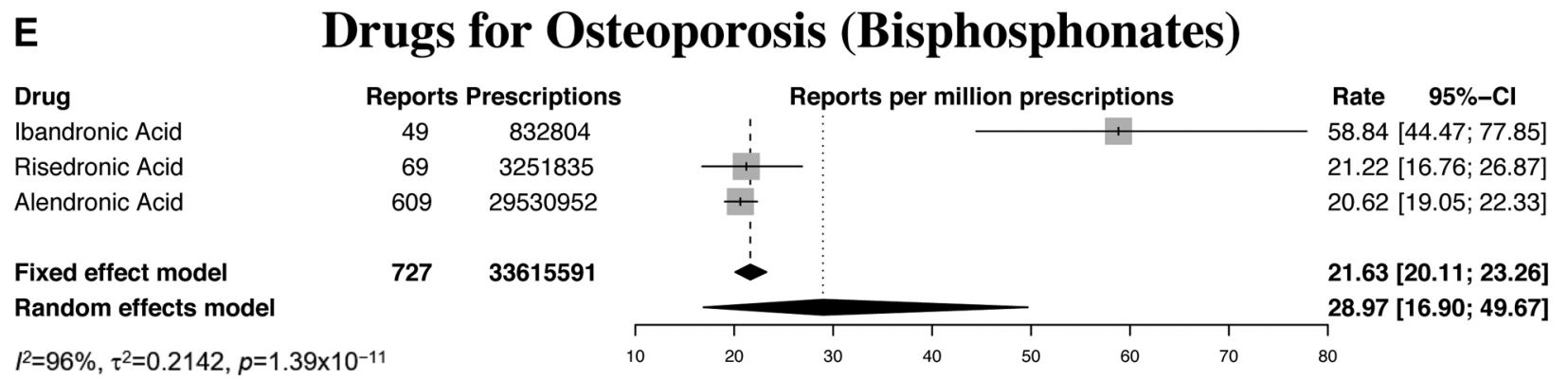

Figure 3. Endocrine system. A) Antidiabetic drugs (Biguanides, Sulfonylureas and Thiazolidinediones), B) Antidiabetic drugs (GLP-1 agonists), C) Antidiabetic drugs (DPP-4 inhibitors), D) Antidiabetic drugs (SGLT-2 inhibitors), E) Drugs for osteoporosis (Bisphosphonates),

\section{Non-Steroidal Anti-inflammatory Drugs}

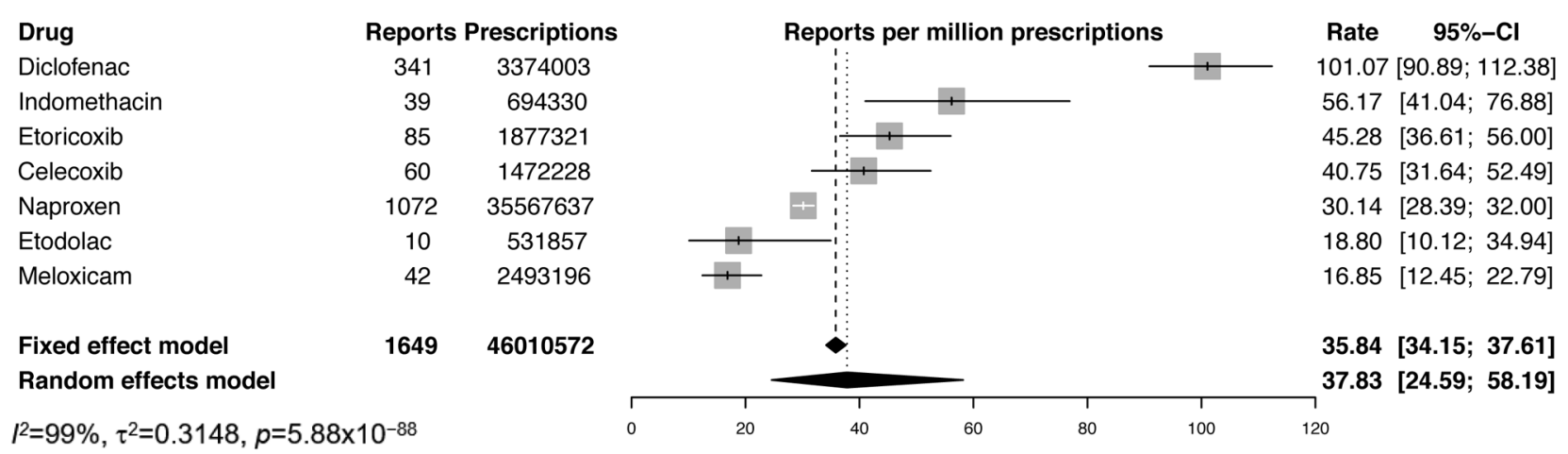

Figure 4. Musculoskeletal and joint diseases - Non-steroidal anti-inflammatory drugs.

\section{Proton Pump Inhibitors}

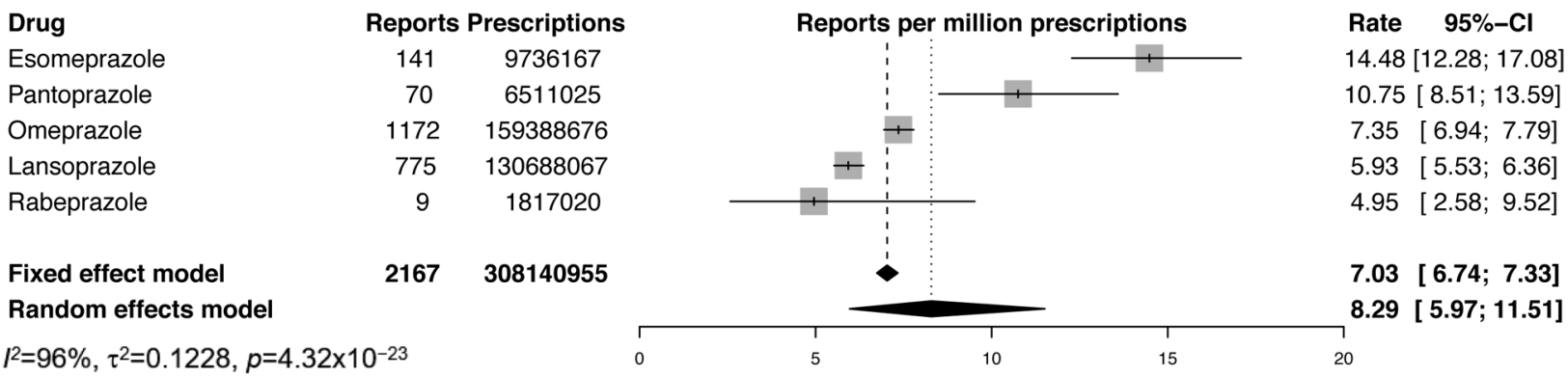

Figure 5. Gastro-intestinal system - Proton pump inhibitors.

(e.g., oral formulation). This can potentially confound data on ADR reports for some medicines, by increasing the number of ADR reports while only including general practice prescribing data.
Prescribing data issues. There are some key issues with the use of general practice prescribing data as the denominator value for calculating the rate of ADR reports per prescribing unit. First, the prescribing data used were obtained from 
A

\section{Drug}

Venlafaxine

Paroxetine

Sertraline

Escitalopram

Mirtazapine

Fluoxetine

Citalopram

Fixed effect mode

Random effects model

$l^{2}=98 \%, \tau^{2}=0.0643, p=1.1 \times 10^{-71}$

B

\section{Drug}

Lorazepam

Oxazepam

Diazepam

Zolpidem

Nitrazepam

Zopiclone

Temazepam

Fixed effect model

Random effects model

$l^{2}=94 \%, \tau^{2}=0.1332, p=7.36 \times 10^{-20}$

\section{Antidepressants}

$\begin{array}{cc}\text { Reports } & \text { Prescriptions } \\ 609 & 22072377 \\ 185 & 6775430 \\ 1822 & 74634061 \\ 125 & 5718539 \\ 858 & 44920641 \\ 564 & 33679459 \\ 926 & 71382441 \\ & \\ \mathbf{5 0 8 9} & \mathbf{2 5 9 1 8 2 9 4 8}\end{array}$

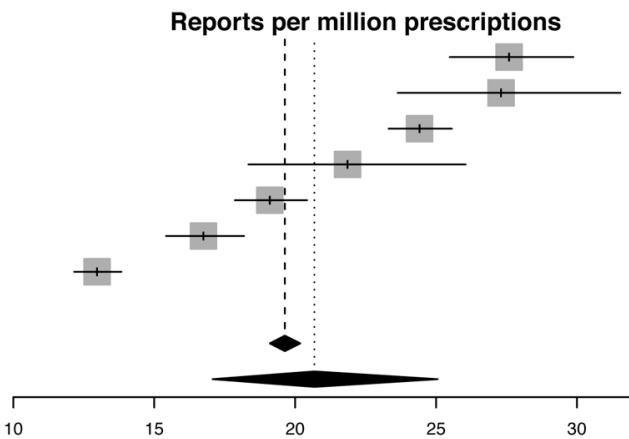

Rate $95 \%-\mathrm{Cl}$

27.59 [25.48; 29.87]

$27.30[23.64 ; 31.54]$

24.41 [23.32; 25.56]

$21.86[18.34 ; 26.05]$

$19.10[17.86 ; 20.42]$

$16.75[15.42 ; 18.19]$

$12.97[12.16 ; 13.84]$

19.63 [19.10; 20.18] 20.68 [17.07; 25.05]

\section{Hypnotics and Anxiolytics}

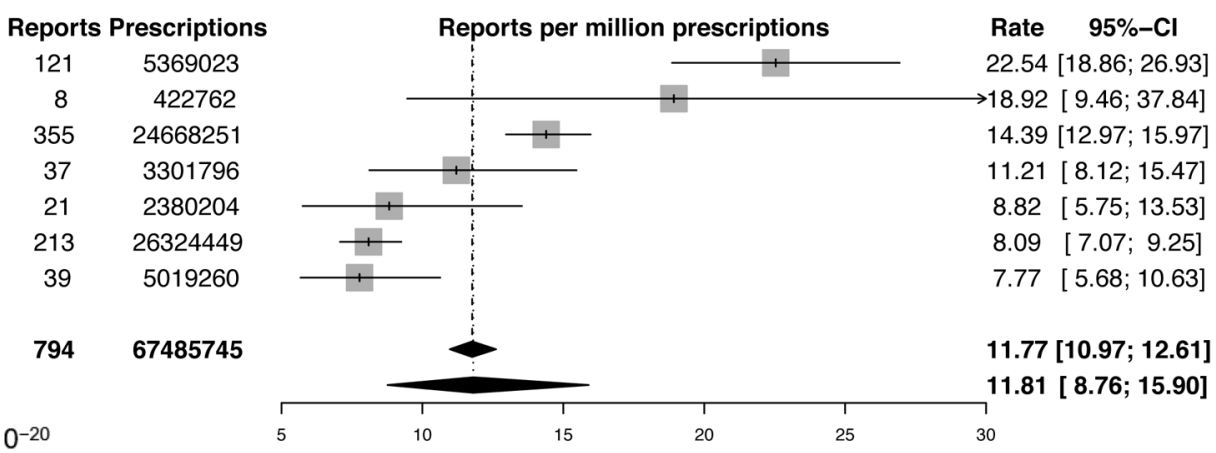

C

Drugs for Dementia

Drug

Rivastigmine

Galantamine

Memantine

Donepezil

Fixed effect model

Random effects model

$I^{2}=94 \%, \tau^{2}=0.1106, p=7.47 \times 10^{-11}$

$\begin{array}{cc}\text { Reports } & \text { Prescription } \\ 90 & 1880370 \\ 25 & 889257 \\ 128 & 6077062 \\ 209 & 10176096 \\ & \\ \mathbf{4 5 2} & \mathbf{1 9 0 2 2 7 8 5}\end{array}$

19022785

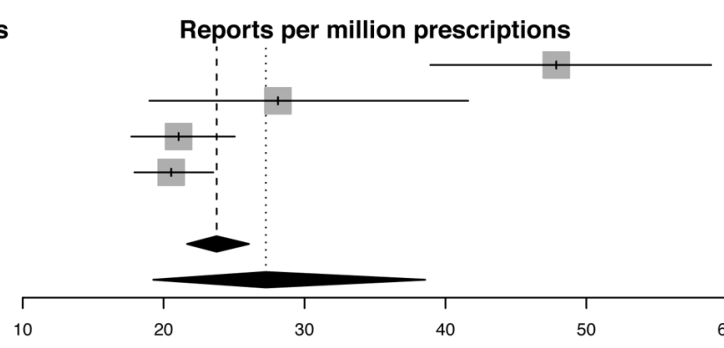

Rate $95 \%-\mathrm{Cl}$ 47.86 [38.93; 58.85] $28.11[19.00 ; 41.61]$ $21.06[17.71 ; 25.05]$ 20.54 [17.93; 23.52]

$23.76[21.67 ; 26.06]$ 27.25 [19.26; 38.56]
D

\section{Drug}

Ondansetron

Metoclopramide

Cyclizine

Domperidone

Prochlorperazine

Fixed effect model

Random effects model

$l^{2}=97 \%, \tau^{2}=0.1933, p=2.6 \times 10^{-25}$

\section{Drugs for Nausea and Vertigo}

$\begin{array}{cc}\text { Reports } & \text { Prescriptions } \\ 75 & 1126719 \\ 195 & 3852341 \\ 144 & 4973741 \\ 59 & 2187964 \\ 151 & 7890087 \\ & \\ \mathbf{6 2 4} & \mathbf{2 0 0 3 0 8 5 2}\end{array}$

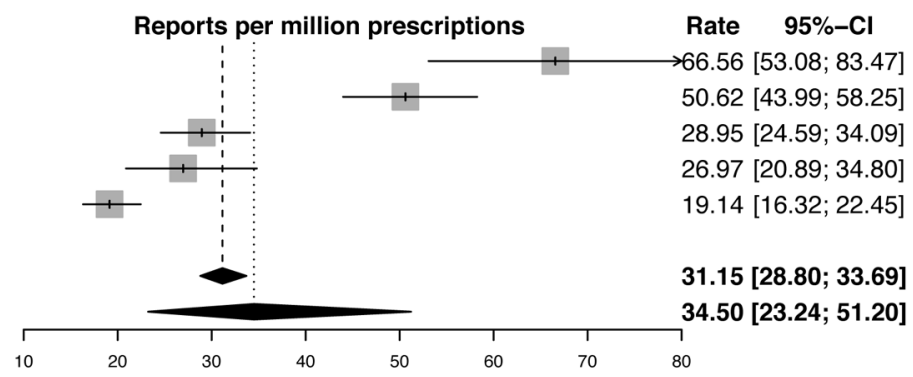

Figure 6. Continued 


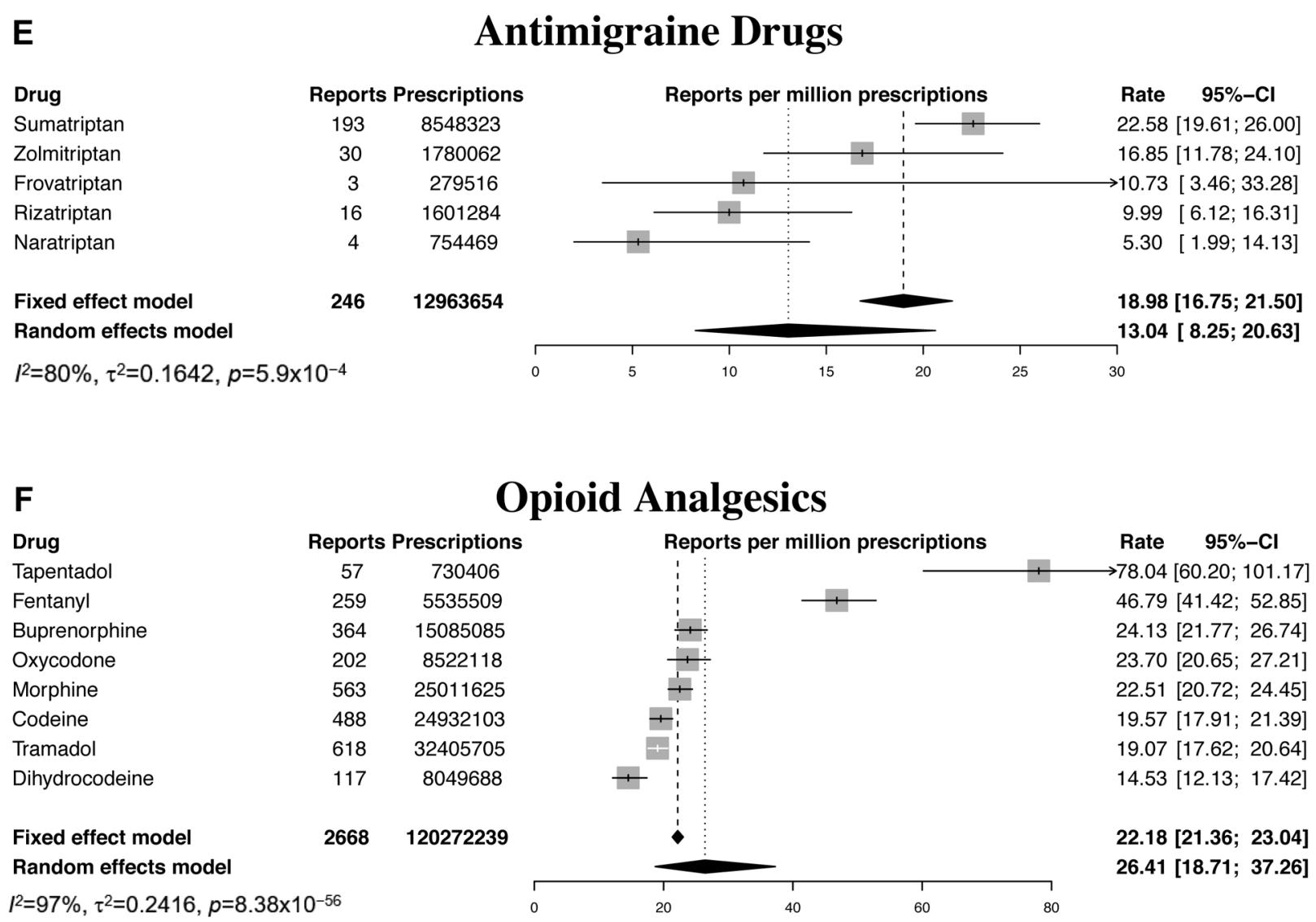

Figure 6. Central nervous system. A) Antidepressants, B) Hypnotics and anxiolytics, C) Drugs for dementia, D) Drugs for nausea and vertigo, E) Antimigraine drugs, F) Opioid analgesics.

prescriptions written only in England. As $84.3 \%$ of the UK population lives in England, England has the vast majority of prescriptions and, therefore, analysing these data reflects the majority of UK general practice prescribing. Whilst it can be assumed that the drug prescribing patterns in the other nations of the UK generate similar ADR reports to the ones used here, this was not tested in this study.

The second issue concerning prescribing data is that their limited scope from general practice alone does not provide a complete overview of prescribing information. In contrast, the Yellow Card database is derived from all UK healthcare settings, including secondary care, Over-the-counter (OTC), Pharmacy medicines (P-medicines) and General Sales List (GSL) medicines purchased in pharmacies or supermarkets that do not require a prescription. Therefore, the use of general practice prescribing data is not representative of the total usage of medicines, and reporting rates for some OTC and GSL as well as P-medicines may have been overrepresented in the yellow card data compared to the prescription data. A limitation of this study is the lack of a systematic process for recording secondary care prescribing data, which has possibly led to missing prescriptions that did not originate from GP practices. However, the majority of prescriptions for medicines are generated in GP practices, as GPs prescribe ongoing supplies for almost all oral medications used in the UK. Although this study may have missed around $20 \%$ of the total UK prescriptions, the majority of them would have been initiated by medical specialists but subsequently repeated by GPs during followup. Therefore, the relative numbers of prescriptions from secondary care are small compared to the ones from general practice and the effect of not including them is likely to be marginal and affect medicines across all therapeutic classes similarly. Moreover, the medicines covered by secondary care prescribing data have little utility for the purposes of our project and this study sought to minimise potential confounding information by excluding medicines prescribed exclusively in the secondary care setting and medicines extensively available as OTC or GSL. While general practice prescribing is robust and collected automatically, there is no 


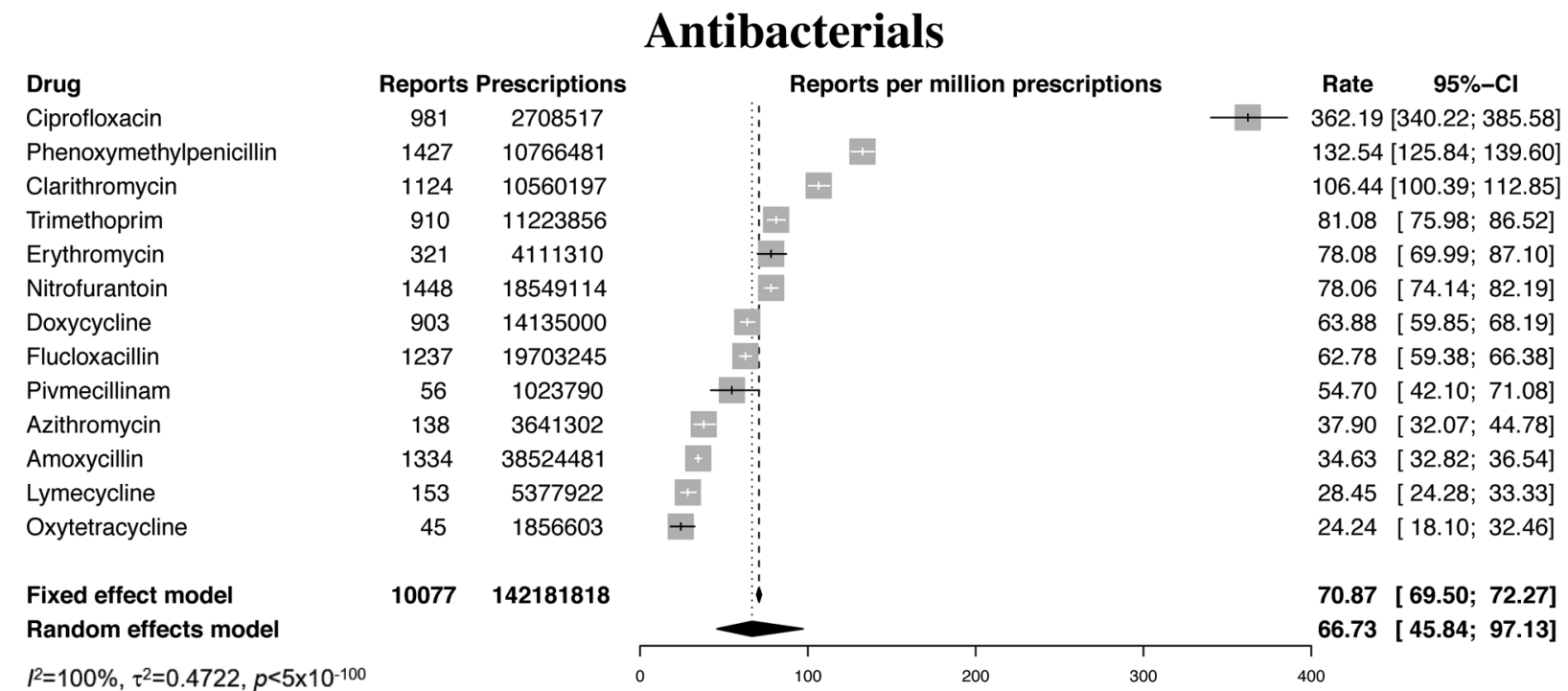

Figure 7. Infections-Antibacterials.

\section{Drugs for Erectile Dysfunction}

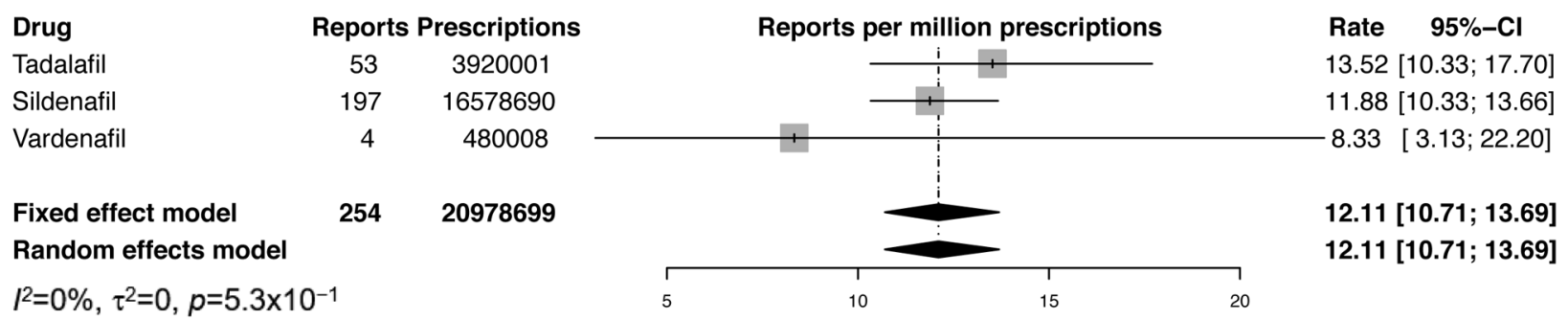

Figure 8. Obstetrics, gynaecology and urinary-tract disorders - drugs for erectile dysfunction.

similar process for exclusively accessing secondary care data. In ideal circumstances and when a comprehensive national database of all secondary care prescriptions becomes available, this work could be extended to include all drugs licensed in the UK and the hospital prescribing data could be combined with the general practice prescribing data.

A third issue is that the prescribing unit used represents the number of times a medicine has been written on a prescription form without providing information on the quantity of medicine prescribed or the length of treatment. While many prescriptions are for one month's supply, some will be for different lengths of treatment. Individual prescriptions may, therefore, contain a range of quantities, from one month's to several months' supply. Nevertheless, the majority of the UK GPs are encouraged to prescribe one month's supply at a time, which may minimise confounding due to this effect.

A fourth issue concerning prescription data, is that they do not necessarily indicate exposure to the medicines as some dispensed prescriptions may not have been taken by patients. Nonetheless, this study used prescriptions that are dispensed as a proxy for actual medicine use, and it is, therefore, likely to be more representative of exposure compared to simple prescribing data. It is estimated that only $87.0-94.7 \%$ of prescriptions generated in primary care are subsequently dispensed $(92,93)$.

Although these issues may affect the precision of the prescribing data used in this study, they are likely to affect all medicines equally, and thus will not affect the relative rates of ADRs. 


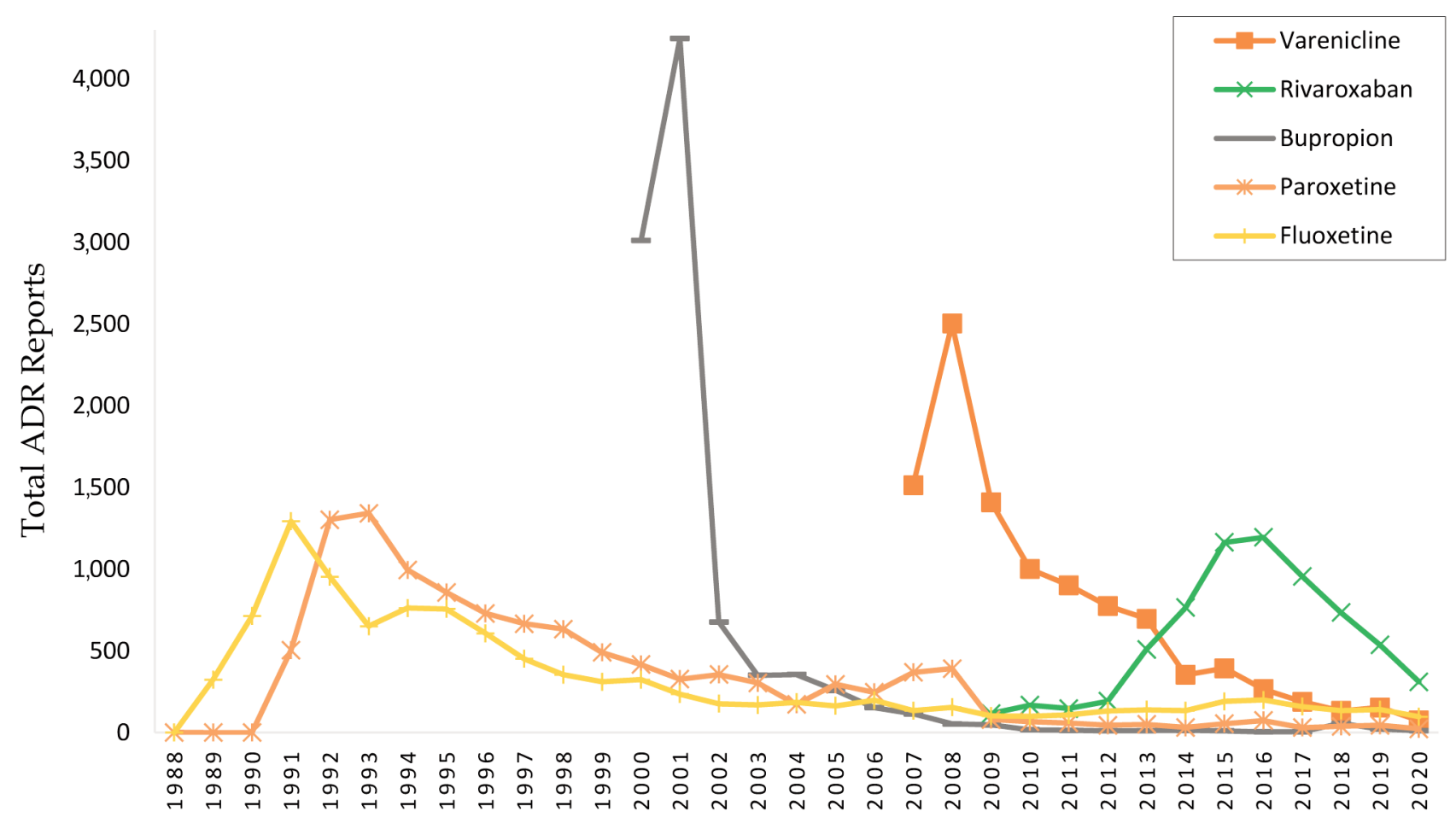

Figure 9. Time trends of the number of ADR reports for some commonly prescribed drugs in general practice from 1988 to 2020.

Adverse drug reaction reporting data issues. Data sourced from pharmacovigilance databases are subject to bias and the use of ADR reporting rates to quantify the risk is to an extent confounded by issues, such as under-reporting, reporting bias, false positives, missing information and duplicate reports. However, Yellow Card database is the only currently available comprehensive resource for ADR reporting at a national level.

First issue concerning the reporting of ADRs is that, except for Marketing Authorisation Holders (MAHs), who have legal obligations to report ADRs associated with the use of their medicines (94-96), reporting is entirely voluntary (43). Studies suggest only a minority of ADRs are reported $(47,97-101)$. It has been estimated that that only $2 \%-4 \%$ of non-serious ADRs are reported via YCS and approximately $90 \%$ of serious ADRs remain unreported (102-105). The rate of ADR reporting by HCPs is falling $(106,107)$, and there has been a $37 \%$ decline in reports over a 9-year period up to 2013 (107). While it has been recently possible to report ADRs through an app on smartphones, occasional anecdotal reports suggest this facility is not widely known (108).

The low proportion of reported ADRs is a global phenomenon that may delay signal detection and underestimate the extent of ADRs (109-113). Incentive payment schemes, legally-required reporting or use of reporting as a quality indicator in the GPs' contracts have been suggested so as to improve ADR reporting rates (114), however, none of them have succeeded to do so in many countries (43). Several studies suggest active training and educational interventions for HCPs on pharmacovigilance may improve their attitude and knowledge of ADR identification and reporting (115-117). Pharmacists are wellpositioned to identify and report ADRs $(43,118-120)$ and the quality of ADR reports submitted by both community and hospital pharmacists have been found to be comparable to reports from hospital doctors (121-124). While continuous education programs can result in short to medium-term improvement in hospital-based settings (125), it is yet to be determined whether such improvements can be sustained in long-term and community-based settings. It has been advocated that ADR reporting and pharmacovigilance education should be vital competencies in undergraduate and postgraduate education $(126,127)$.

Several other factors contribute to under-reporting of ADRs, such as the seriousness of the ADR and the familiarity with it or the medication causing it (128). Although there is undoubtedly extensive under-reporting of minor ADRs that have no significant disadvantageous effects on the patient, serious and fatal ADR reports are more notable and more likely to be reported. Patients with serious ADRs are also expected to be hospitalised or treated under hospital care, and, consequently, more likely to be reported. In addition, it is mandatory for 

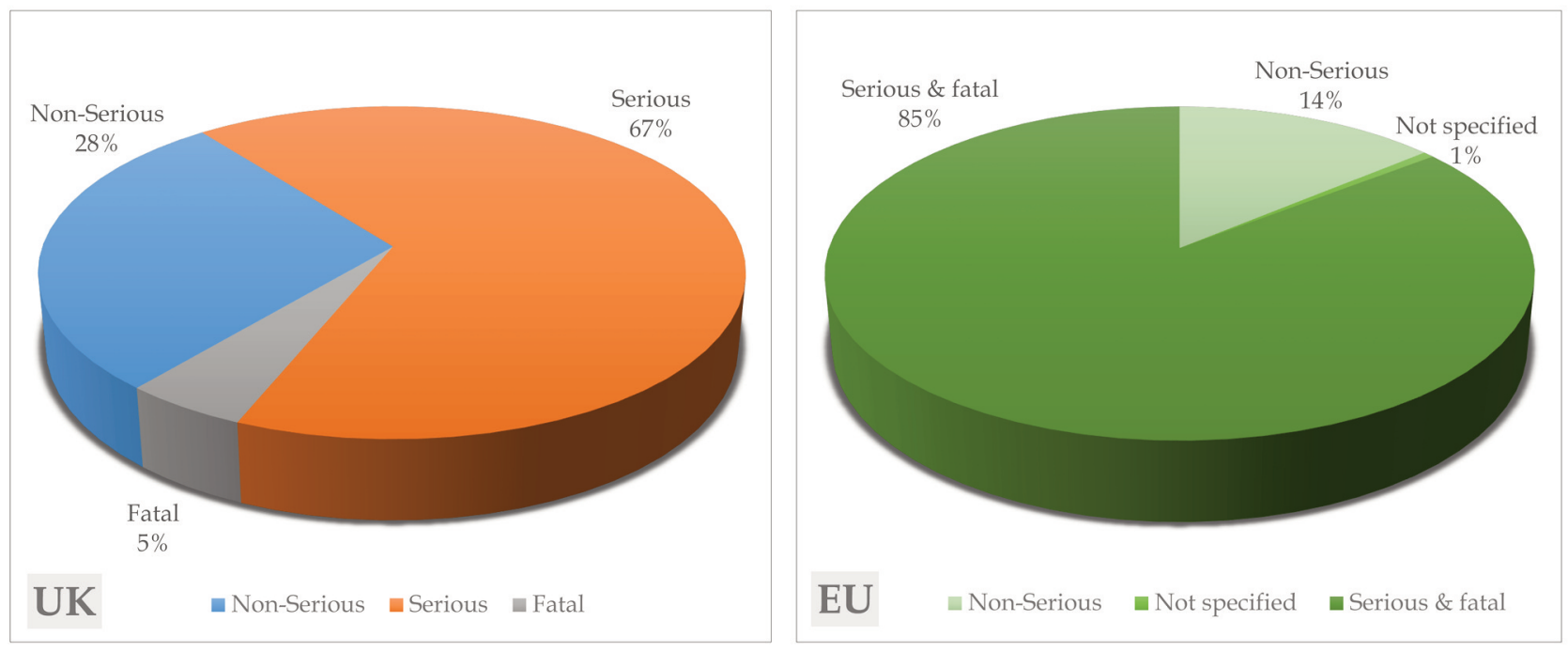

\begin{tabular}{|c|c|c|c|c|c|c|c|}
\hline $\begin{array}{c}\text { Pharmacovigilance } \\
\text { database }\end{array}$ & $\begin{array}{c}\text { Number of } \\
\text { medicinal products }\end{array}$ & $\begin{array}{c}\text { Non-Serious } \\
\text { reports }\end{array}$ & $\begin{array}{c}\text { Not specified } \\
\text { reports }\end{array}$ & $\begin{array}{c}\text { Serious } \\
\text { reports }\end{array}$ & $\begin{array}{c}\text { Fatal } \\
\text { reports }\end{array}$ & $\begin{array}{c}\text { Serious \& fatal } \\
\text { reports }\end{array}$ & $\begin{array}{c}\text { Total } \\
\text { reports }\end{array}$ \\
\hline UK 'Yellow Card' & 2,331 & 301,449 & - & 707,661 & 52,255 & 759,916 & $1,061,365$ \\
\hline EU 'EudraVigilance' & 2,521 & $1,159,770$ & 48,954 & - & - & $7,139,343$ & $8,348,067$ \\
\hline
\end{tabular}

Figure 10. Analyses of the ADR reports in both the UK's Yellow Card database from inception until September 2020 and the European pharmacovigilance database 'EudraVigilance' from inception until November 2020.

MAHs to report all serious ADRs related to their medication to MHRA and therefore less prone to under-reporting. Our analysis of the ADR reports in both the UK's Yellow Card and the European pharmacovigilance databases has shown that 72$85 \%$ of all ADR reports were serious and fatal, with similar findings in other databases (129). This suggests that the extent to which underreporting is likely to significantly skew our findings across different medicines is small. Exceptions may include very old medicines and medicines with familiar ADRs, as a significant trigger for reporting is likely to be the novelty of drugs or novelty of ADRs.

Second issue concerning the reporting of ADRs is that the number of ADR reports for a medicine can be biasedly subject to higher or lower levels of reporting compared to other medicines. Public awareness and media coverage on a safety issue related to a particular medicine, or assigning a certain medicine to a patient support program, can affect the number of ADR reports for this medicine. Moreover, ADRs to the first drug of a new therapeutic class, such as statins, will be novel and more likely to be reported, but as more drugs within that class are released, similar ADRs may be assumed to be class-related effects and thus not reported. Reporting rates for newly-licensed medicines or medicines on the Black Triangle Additional Monitoring list $(\boldsymbol{\nabla})$ are likely to be higher than older medicines in the few years following authorisation, however, they gradually decline over time even if the medicine is progressively used more broadly (130).

Therefore, the relatively higher reporting rate for newly licensed medicines and medicines on the Black Triangle scheme may be due to this time-trend effect, rather than inherent safety issues. Analysing all ADRs within the first five years from the introduction of each medicine to the market may reduce this effect. Unless all medicines within a class are introduced into the market around the same time, comparative figures based on reporting rates within a restricted timeframe can be misleading. However, this is less likely to considerably skew our results as the number of newly-licensed medicines and medicines with Black Triangle status that are included in our analysis is very small (Table I).

Third issue concerning the reporting of ADRs, is that the MHRA encourages HCPs and patients to submit a report on a given medicine, even though they are not certain that it caused this ADR. This may result in false positive reports, and, therefore, further analyses may need to be undertaken to confirm possible associations. Establishing causality is a challenge, particularly when other medicines have been administered simultaneously or there is a long delay between initiation of medicine and the appearance of the ADR (131). The incidence of erroneous reports by pharmacists and physicians is high, often with difficulty in accurately determining the causality of ADRs (132). Cases of misuse, 
Table I. The newly-licensed medicines of the past 10 years \& medicines on the Black Triangle Additional Monitoring list ( $\mathbf{\nabla})$ included in our analyses.

\begin{tabular}{lc}
\hline Medicine & Year of approval or Black Triangle status \\
\hline Rivaroxaban & $\boldsymbol{\nabla}$ \\
Semaglutide & 2016 \\
Edoxaban & 2015 \\
Dulaglutide & 2014 \\
Canagliflozin & 2014 \\
Empagliflozin & 2014 \\
Alogliptin & 2013 \\
Lixisenatide & 2013 \\
Dapagliflozin & 2011 \\
Linagliptin & 2011 \\
Ticagrelor & 2011 \\
Tapentadol & \\
\hline
\end{tabular}

abuse, medication errors, occupational exposure and administration, or dispensing errors may also affect the number of reports submitted.

Fourth, the quality of reports submitted by patients compared to HCPs can be unreliable (133). While patients can provide many distinct ADR types from a different perspective, resulting in broader information that should not be dismissed (102, 134-141), often patients' inability to accurately describe the seriousness of incidents may impact the data $(134,142)$. Medical seriousness as per CIOMS official criteria may differ from patients' perception of what represents a "serious" ADR (143). Studies have shown mixed results on whether HCPs compared to patients are less or more prone to submit serious and life-threatening ADR reports $(133,136,142,144-148)$. Analysis of the Danish ADR database has demonstrated that the share of 'serious' ADRs submitted by patients is similar to that of GPs, yet lower than that of other HCPs (148), which may help detect safety signals earlier than if ADR reports from HCPs alone were relied on (149-151).

In conclusion, to the best of our knowledge, this is the first and largest assessment of the suitability of mapping ADR reporting data from the Yellow Card database onto the general practice prescribing data. This proof-of-concept study created generally applicable rules to execute this linkage and demonstrated the feasibility of using real-time real-world prescribing data in conjunction with ADR reporting data to compare the safety profiles of medicines. To allow for more precise and accurate data integration, future work should focus on improving ADR reporting data and incorporating prescriptions for secondary care and private prescriptions.

In addition to predicting medicine safety, the comparative safety charts provide a potential resource for policy makers and represent a benchmark against which to compare findings from pharmaco-epidemiological studies investigating high-risk medicines. Even with the acknowledged limitations that might considerably affect the quality of the data, dissemination of these charts has the potential to support informed decisionmaking regarding a patient's treatment regimen and can, therefore, be useful for prescribers and pharmacists counselling patients on medications. Nevertheless, a comprehensive benefit-risk assessment based on the patient's overall risks and other patient-specific data in conjunction with the product information should be considered. A follow-up step to validate these comparative charts and test of their suitability for clinical practice is also warranted.

\section{Conflicts of Interest}

All Authors declare that they have no conflicts of interest that are directly relevant to the content of this study.

\section{Authors' Contributions}

$\mathrm{KM}, \mathrm{RD}$ and LJ conceptualised the study and designed the research. $\mathrm{KM}$ conducted the research and graphical overviews. MNW performed the statistical analysis and generated the graphs.

\section{References}

1 Davies EC, Green CF, Taylor S, Williamson PR, Mottram DR and Pirmohamed M: Adverse drug reactions in hospital in-patients: a prospective analysis of 3695 patient-episodes. PLoS One 4(2): e4439, 2009. PMID: 19209224. DOI: 10.1371/journal.pone. 0004439

2 Pirmohamed M, James S, Meakin S, Green C, Scott AK, Walley TJ, Farrar K, Park BK and Breckenridge AM: Adverse drug reactions as cause of admission to hospital: prospective analysis of 18820 patients. BMJ 329(7456): 15-19, 2004. PMID: 15231615. DOI: 10.1136/bmj.329.7456.15

3 Gallagher RM, Mason JR, Bird KA, Kirkham JJ, Peak M, Williamson PR, Nunn AJ, Turner MA, Pirmohamed M and Smyth RL: Adverse drug reactions causing admission to a 
paediatric hospital. PLoS One 7(12): e50127, 2012. PMID: 23226510. DOI: 10.1371/journal.pone.0050127

4 Beijer HJ and de Blaey CJ: Hospitalisations caused by adverse drug reactions (ADR): a meta-analysis of observational studies. Pharm World Sci 24(2): 46-54, 2002. PMID: 12061133. DOI: 10.1023/a:1015570104121

5 Davies EC, Green CF, Mottram DR and Pirmohamed M: Adverse drug reactions in hospitals: a narrative review. Curr Drug Saf 2(1): 79-87, 2007. PMID: 18690953. DOI: 10.2174/ 157488607779315507

6 Lazarou J, Pomeranz BH and Corey PN: Incidence of adverse drug reactions in hospitalized patients: a meta-analysis of prospective studies. JAMA 279(15): 1200-1205, 1998. PMID: 9555760. DOI: $10.1001 /$ jama.279.15.1200

7 Hitchen L: Adverse drug reactions result in 250,000 UK admissions a year. BMJ 332(7550): 1109, 2006. PMID: 16690649. DOI: 10.1136/bmj.332.7550.1109

8 Frontier Economics: Exploring the costs of unsafe care in the NHS. Frontier Economics Ltd, London, pp 1-31, 2014. Available at: https://www.frontier-economics.com/media/2459/exploringthe-costs-of-unsafe-care-in-the-nhs-frontier-report-2-2-2-2.pdf [Last accessed on February 11, 2022]

9 Insani WN, Whittlesea C, Alwafi H, Man KKC, Chapman S and Wei L: Prevalence of adverse drug reactions in the primary care setting: A systematic review and meta-analysis. PLoS One 16(5): e0252161, 2021. PMID: 34038474. DOI: 10.1371/journal.pone. 0252161

10 The Council for International Organizations of Medical Sciences: Reporting adverse drug reactions: definitions of terms and criteria for their use. CIOMS, 1999. Available at: https://cioms.ch/wpcontent/uploads/2017/01/reporting_adverse_drug.pdf [Last accessed on February 12, 2022]

11 McDonnell PJ and Jacobs MR: Hospital admissions resulting from preventable adverse drug reactions. Ann Pharmacother 36(9): 1331-1336, 2002. PMID: 12196047. DOI: 10.1345/aph.1A333

12 Keche Y, Gaikwad N and Dhaneria S: Preventability, predictability, severity and causality assessment of adverse drug reactions reported from a teaching hospital in chhattisgarh: A retrospective analysis. J Family Med Prim Care 10(7): 2541-2545, 2021. PMID: 34568133. DOI: 10.4103/jfmpc.jfmpc_2374_20

13 Vora MB, Trivedi HR, Shah BK and Tripathi CB: Adverse drug reactions in inpatients of internal medicine wards at a tertiary care hospital: A prospective cohort study. J Pharmacol Pharmacother 2(1): 21-25, 2011. PMID: 21701642. DOI: 10.4103/0976-500X.77102

14 Bates DW, Cullen DJ, Laird N, Petersen LA, Small SD, Servi D, Laffel G, Sweitzer BJ, Shea BF and Hallisey R: Incidence of adverse drug events and potential adverse drug events. Implications for prevention. ADE Prevention Study Group. JAMA 274(1): 29-34, 1995. PMID: 7791255.

15 Ducharme MM and Boothby LA: Analysis of adverse drug reactions for preventability. Int J Clin Pract 61(1): 157-161, 2007. PMID: 17229189. DOI: 10.1111/j.1742-1241.2006.01130.x

16 Rogers S, Wilson D, Wan S, Griffin M, Rai G and Farrell J: Medication-related admissions in older people: a crosssectional, observational study. Drugs Aging 26(11): 951-961, 2009. PMID: 19848440. DOI: 10.2165/11316750-00000000000000

17 Hakkarainen KM, Hedna K, Petzold M and Hägg S: Percentage of patients with preventable adverse drug reactions and preventability of adverse drug reactions - a meta-analysis. PLoS One 7(3): e33236, 2012. PMID: 22438900. DOI: 10.1371/journal. pone.0033236

18 Martin K, Bégaud B, Latry P, Miremont-Salamé G, Fourrier A and Moore N: Differences between clinical trials and postmarketing use. Br J Clin Pharmacol 57(1): 86-92, 2004. PMID: 14678345. DOI: 10.1046/j.1365-2125.2003.01953.x

19 Charlton BG and Miles A: The rise and fall of EBM. QJM 91(5): 371-374, 1998. PMID: 9709472. DOI: 10.1093/qjmed/ 91.5.371

20 Hampton JR: Size isn't everything. Stat Med 21(19): 28072814, 2002. PMID: 12325096. DOI: $10.1002 / \mathrm{sim} .1284$

21 Evans JG: Evidence-based and evidence-biased medicine. Age Ageing 24(6): 461-463, 1995. PMID: 8588532. DOI: 10.1093/ageing/24.6.461

22 Caplan LR: Evidence based medicine: concerns of a clinical neurologist. J Neurol Neurosurg Psychiatry 71(5): 569-574, 2001. PMID: 11606661. DOI: 10.1136/jnnp.71.5.569

23 Feinstein AR and Horwitz RI: Problems in the "evidence" of "evidence-based medicine". Am J Med 103(6): 529-535, 1997. PMID: 9428837. DOI: 10.1016/s0002-9343(97)00244-1

24 Naylor CD: Grey zones of clinical practice: some limits to evidence-based medicine. Lancet 345(8953): 840-842, 1995. PMID: 7898234. DOI: 10.1016/s0140-6736(95)92969-x

25 Rothwell PM: External validity of randomised controlled trials: "to whom do the results of this trial apply?". Lancet 365(9453): 82-93, 2005. PMID: 15639683. DOI: 10.1016/S01406736(04)17670-8

26 Leroy F, Dauxois JY, Théophile H, Haramburu F and TubertBitter P: Estimating time-to-onset of adverse drug reactions from spontaneous reporting databases. BMC Med Res Methodol 14: 17, 2014. PMID: 24490673. DOI: 10.1186/1471-2288-14-17

27 Amery WK and ISPE: Why there is a need for pharmacovigilance. Pharmacoepidemiol Drug Saf 8(1): 61-64, 1999. PMID: 15073950. DOI: $10.1002 /($ SICI)1099-1557 (199901/02)8:1<61::AID-PDS395>3.0.CO;2-A

28 Hoffman KB, Dimbil M, Erdman CB, Tatonetti NP and Overstreet BM: The Weber effect and the United States Food and Drug Administration's Adverse Event Reporting System (FAERS): analysis of sixty-two drugs approved from 2006 to 2010. Drug Saf 37(4): 283-294, 2014. PMID: 24643967. DOI: $10.1007 / \mathrm{s} 40264-014-0150-2$

29 Ishiguro C, Hall M, Neyarapally GA and Dal Pan G: Postmarket drug safety evidence sources: an analysis of FDA drug safety communications. Pharmacoepidemiol Drug Saf 21(10): 1134-1136, 2012. PMID: 23033257. DOI: 10.1002/pds.3317

30 Black N: Why we need observational studies to evaluate the effectiveness of health care. BMJ 312(7040): 1215-1218, 1996. PMID: 8634569. DOI: 10.1136/bmj.312.7040.1215

31 Nichol AD, Bailey M, Cooper DJ, POLAR and EPO Investigators: Challenging issues in randomised controlled trials. Injury 41(Suppl 1): S20-S23, 2010. PMID: 20413119. DOI: $10.1016 /$ j.injury.2010.03.033

32 Hannan EL: Randomized clinical trials and observational studies: guidelines for assessing respective strengths and limitations. JACC Cardiovasc Interv 1(3): 211-217, 2008. PMID: 19463302. DOI: 10.1016/j.jcin.2008.01.008

33 Yang W, Zilov A, Soewondo P, Bech OM, Sekkal F and Home PD: Observational studies: going beyond the boundaries of randomized controlled trials. Diabetes Res Clin Pract 88 Suppl 
1: S3-S9, 2010. PMID: 20466165. DOI: 10.1016/S01688227(10)70002-4

34 Bartlett C, Doyal L, Ebrahim S, Davey P, Bachmann M, Egger $\mathrm{M}$ and Dieppe $\mathrm{P}$ : The causes and effects of socio-demographic exclusions from clinical trials. Health Technol Assess 9(38): iiiiv, ix-x, 1-152, 2005. PMID: 16181564. DOI: 10.3310/hta9380

35 Walker MC and Sander JW: Difficulties in extrapolating from clinical trial data to clinical practice: the case of antiepileptic drugs. Neurology 49(2): 333-337, 1997. PMID: 9270558. DOI: 10.1212/wnl.49.2.333

36 Binnie CD: Design of clinical antiepileptic drug trials. Seizure 4(3): 187-192, 1995. PMID: 7582652. DOI: 10.1016/s10591311(05)80059-7

37 Gilbody S, Wahlbeck K and Adams C: Randomized controlled trials in schizophrenia: a critical perspective on the literature. Acta Psychiatr Scand 105(4): 243-251, 2002. PMID: 11942927. DOI: $10.1034 / \mathrm{j} .1600-0447.2002 .00242 . \mathrm{x}$

38 Lasser KE, Allen PD, Woolhandler SJ, Himmelstein DU, Wolfe SM and Bor DH: Timing of new black box warnings and withdrawals for prescription medications. JAMA 287(17): 22152220, 2002. PMID: 11980521. DOI: 10.1001/jama.287.17.2215

39 Pacurariu AC, Coloma PM, van Haren A, Genov G, Sturkenboom MC and Straus SM: A description of signals during the first 18 months of the EMA pharmacovigilance risk assessment committee. Drug Saf 37(12): 1059-1066, 2014. PMID: 25398646. DOI: 10.1007/s40264-014-0240-1

40 Hernandez García C, Pinheiro L, Ángel Maciá M, Stroe R, Georgescu A, Dondera R and Cserjés ZS: Spontaneous adverse drug reactions: subgroup report, 2018. Available at: https://www.ema.europa.eu/en/documents/report/spontaneousadverse-drug-reactions-subgroup-report_en.pdf [Last accessed on February 12, 2022]

41 Păcurariu A: The role of signal detection in Pharmacovigilance, 2018. Available at: https://repub.eur.nl/pub/106001/ThesisAPacurariu.pdf [Last accessed on February 12, 2022]

42 The Medicines and Healthcare products Regulatory Agency: Yellow Card Scheme - MHRA. Available at: https://yellowcard mhra.gov.uk/idaps [Last accessed on February 12, 2022]

43 Independent Steering Committee: Report of an independent review of access to the yellow card scheme. TSO (The Stationery Office), London, 2004. Available at: https://solidaritessante.gouv.fr/IMG/pdf/Report_of_an_Independent_Review_of_Ac cess_to_the_Yellow_Card_Scheme.pdf [Last accessed on February 12, 2022]

44 de Bie S, Ferrajolo C, Straus SM, Verhamme KM, Bonhoeffer J, Wong IC, Sturkenboom MC and GRiP network: Pediatric drug safety surveillance in FDA-AERS: a description of adverse events from GRiP project. PLoS One 10(6): e0130399, 2015. PMID: 26090678. DOI: 10.1371/journal.pone.0130399

45 Robb MA, Racoosin JA, Sherman RE, Gross TP, Ball R, Reichman ME, Midthun K and Woodcock J: The US Food and Drug Administration's Sentinel Initiative: expanding the horizons of medical product safety. Pharmacoepidemiol Drug Saf 21(Suppl 1): 9-11, 2012. PMID: 22262587. DOI: 10.1002/pds.2311

46 Pacurariu AC, Straus SM, Trifirò G, Schuemie MJ, Gini R, Herings R, Mazzaglia G, Picelli G, Scotti L, Pedersen L, Arlett P, van der Lei J, Sturkenboom MC and Coloma PM: Useful Interplay Between Spontaneous ADR Reports and Electronic Healthcare Records in Signal Detection. Drug Saf 38(12): 1201-1210, 2015. PMID: 26370104. DOI: 10.1007/s40264-015-0341-5
47 Huang YL, Moon J and Segal JB: A comparison of active adverse event surveillance systems worldwide. Drug Saf 37(8): 581-596, 2014. PMID: 25022829. DOI: 10.1007/s40264-0140194-3

48 Loke YK, Derry S and Aronson JK: A comparison of three different sources of data in assessing the frequencies of adverse reactions to amiodarone. Br J Clin Pharmacol 57(5): 616-621, 2004. PMID: 15089815. DOI: 10.1111/j.0306-5251.2003.02055.x

49 Hauben $M$ and Zhou $X$ : Quantitative methods in pharmacovigilance: focus on signal detection. Drug Saf 26(3): 159-186, 2003. PMID: 12580646. DOI: 10.2165/00002018200326030-00003

50 Herings RM and Erkens JA: Increased suicide attempt rate among patients interrupting use of atypical antipsychotics. Pharmacoepidemiol Drug Saf 12(5): 423-424, 2003. PMID: 12899119. DOI: $10.1002 /$ pds.837

51 Herings RM, Urquhart $\mathrm{J}$ and Leufkens HG: Venous thromboembolism among new users of different oral contraceptives. Lancet 354(9173): 127-128, 1999. PMID: 10408492. DOI: $10.1016 / \mathrm{s} 0140-6736(99) 01257-\mathrm{x}$

52 Coloma PM, Trifirò G, Patadia V and Sturkenboom M: Postmarketing safety surveillance : where does signal detection using electronic healthcare records fit into the big picture? Drug Saf 36(3): 183-197, 2013. PMID: 23377696. DOI: 10.1007/ s40264-013-0018-x

53 Wood L and Martinez C: The general practice research database: role in pharmacovigilance. Drug Saf 27(12): 871-881, 2004. PMID: 15366975. DOI: 10.2165/00002018-20042712000004

54 Evans JM and MacDonald TM: Record-linkage for pharmacovigilance in Scotland. Br J Clin Pharmacol 47(1): 105-110, 1999. PMID: 10073747. DOI: 10.1046/j.1365-2125.1999.00853.x

55 Microsoft Office Professional Plus Excel®, 2016. Available at: https://support.microsoft.com/en-us/office/download-andinstall-or-reinstall-office-2019-office-2016-or-office-20137c695b06-6d1a-4917-809c-98ce43f86479 [Last accessed on February 12, 2022]

56 EBM DataLab U of O: All chemicals I OpenPrescribing, 2017. Available at: https://openprescribing.net/chemical/ [Last accessed on March 28, 2021]

57 'High-alert medicines' working group 2008-10: Report on "Medicines most frequently involved in serious adverse drug events". Copenhagen, 2011. Available at: https://laegemid delstyrelsen.dk/en/publications/2011/publication-on-medicinesmost-frequently-involved-in-serious-adverse-drugevents/ /media/D351DCAA2DB4463498724643F4E876C6.ashx [Last accessed on February 12, 2022]

58 Balduzzi S, Rücker G and Schwarzer G: How to perform a meta-analysis with R: a practical tutorial. Evid Based Ment Health 22(4): 153-160, 2019. PMID: 31563865. DOI: 10.1136/ ebmental-2019-300117

59 Stijnen T, Hamza TH and Ozdemir P: Random effects metaanalysis of event outcome in the framework of the generalized linear mixed model with applications in sparse data. Stat Med 29(29): 3046-3067, 2010. PMID: 20827667. DOI: 10.1002/ $\operatorname{sim} .4040$

60 Bagos P and Nikolopoulos G: Mixed-effects poisson regression models for meta-analysis of follow-up studies with constant or varying durations. The International Journal of Biostatistics 5(1): ar21, 2021. DOI: $10.2202 / 1557-4679.1168$ 
61 Higgins JP, Thompson SG, Deeks JJ and Altman DG: Measuring inconsistency in meta-analyses. BMJ 327(7414): 557-560, 2003. PMID: 12958120. DOI: $10.1136 / \mathrm{bmj}$. 327.7414 .557

62 Higgins JP and Thompson SG: Quantifying heterogeneity in a meta-analysis. Stat Med 21(11): 1539-1558, 2002. PMID: 12111919. DOI: $10.1002 / \mathrm{sim} .1186$

63 Viechtbauer W: Bias and efficiency of meta-analytic variance estimators in the random-effects model. Journal of Educational and Behavioral Statistics 30(3): 261-293, 2021. DOI: 10.3102/10769986030003261

64 General Medical Council: Outcomes for graduates. GMC Publ, pp 1-28, 2018. Available at: https://www.gmc-uk.org/-/ media/documents/dc11326-outcomes-for-graduates-2018_pdf75040796.pdf [Last accessed on February 12, 2022]

65 General Pharmaceutical Council: In practice: Guidance for pharmacist prescribers, pp 1-32, 2019. Available at: https://www.pharmacyregulation.org/sites/default/files/docume nt/in-practice-guidance-for-pharmacist-prescribers-february2020.pdf [Last accessed on February 12, 2022]

66 Medicines and Healthcare Products Regulatory Agency (MHRA): Trends in UK spontaneous Adverse Drug Reaction (ADR) reporting between 2008-2012. London, 2014. Available at: https://webarchive.nationalarchives.gov.uk/ukgwa/201412061932 08/http://www.mhra.gov.uk/home/groups/pl-p/documents/ websiteresources/con408250.pdf [Last accessed on February 12, 2022]

67 Tyynismaa L, Honkala A, Airaksinen M, Shermock K and Lehtonen L: Identifying high-alert medications in a university hospital by applying data from the medication error reporting system. J Patient Saf 17(6): 417-424, 2021. PMID: 28574956. DOI: $10.1097 /$ PTS.0000000000000388

68 Franke HA, Woods DM and Holl JL: High-alert medications in the pediatric intensive care unit. Pediatr Crit Care Med 10(1): 85-90, 2009. PMID: 19057440. DOI: 10.1097/PCC.0b013e3181936ff8

69 Saedder EA, Brock B, Nielsen LP, Bonnerup DK and Lisby M: Identifying high-risk medication: a systematic literature review. Eur J Clin Pharmacol 70(6): 637-645, 2014. PMID: 24671697. DOI: $10.1007 / \mathrm{s} 00228-014-1668-\mathrm{z}$

70 Institute for Safe Medication Practices (ISMP): High-Alert Medications in Acute Care Settings, 2018. Available at: https://www.ismp.org/sites/default/files/attachments/201808/highAlert2018-Acute-Final.pdf [Last accessed on February 12, 2022]

71 NHS Specialist Pharmacy Service: Specimen High Risk Injectable Medicines List, 2016. Available at: https://www.sps.nhs.uk/wpcontent/uploads/2016/12/Specimen-high-risk-list-Version-3_Final28thNov16.pdf [Last accessed on February 12, 2022]

72 Institute for Safe Medication Practices (ISMP): List of High-Aler Medications in Community/Ambulatory Healthcare, 2011. Available at: https://www.ismp.org/sites/default/files/attachments/ 2017-11/highAlert-community.pdf [Last accessed on February 12, 2022]

73 Institute for Safe Medication Practices (ISMP): High-Alert Medications in Long-Term Care (LTC) Settings, 2017. Available at: https://www.ismp.org/sites/default/files/attachments/2017 11/LTC-High-Alert-List.pdf [Last accessed on February 12, 2022]

74 Federico F: Preventing harm from high-alert medications. Jt Comm J Qual Patient Saf 33(9): 537-542, 2007. PMID: 17915527. DOI: 10.1016/s1553-7250(07)33057-2
75 Hanlon JT, Schmader KE, Samsa GP, Weinberger M, Uttech KM, Lewis IK, Cohen HJ and Feussner JR: A method for assessing drug therapy appropriateness. J Clin Epidemiol 45(10): 1045-1051, 1992. PMID: 1474400. DOI: 10.1016/08954356(92)90144-c

76 Samsa GP, Hanlon JT, Schmader KE, Weinberger M, Clipp EC, Uttech KM, Lewis IK, Landsman PB and Cohen HJ: A summated score for the medication appropriateness index: development and assessment of clinimetric properties including content validity. J Clin Epidemiol 47(8): 891-896, 1994. PMID: 7730892. DOI: 10.1016/0895-4356(94)90192-9

77 Barry PJ, O'Keefe N, O'Connor KA and O'Mahony D: Inappropriate prescribing in the elderly: a comparison of the Beers criteria and the improved prescribing in the elderly tool (IPET) in acutely ill elderly hospitalized patients. J Clin Pharm Ther 31(6): 617-626, 2006. PMID: 17176367. DOI: 10.1111/j.1365-2710.2006.00783.x

78 Barry PJ, Gallagher P, Ryan C and O'mahony D: START (screening tool to alert doctors to the right treatment) - an evidence-based screening tool to detect prescribing omissions in elderly patients. Age Ageing 36(6): 632-638, 2007. PMID: 17881418. DOI: $10.1093 /$ ageing/afm 118

79 Gallagher P, Ryan C, Byrne S, Kennedy J and O'Mahony D: STOPP (screening tool of older person's prescriptions) and START (screening tool to alert doctors to right treatment). Consensus validation. Int J Clin Pharmacol Ther 46(2): 72-83, 2008. PMID: 18218287 . DOI: $10.5414 / \mathrm{cpp} 46072$

80 Lavan $\mathrm{AH}$ and Gallagher P: Predicting risk of adverse drug reactions in older adults. Ther Adv Drug Saf 7(1): 11-22, 2016. PMID: 26834959. DOI: 10.1177/2042098615615472

81 Christensen M and Lundh A: Medication review in hospitalised patients to reduce morbidity and mortality. Cochrane Database Syst Rev 2: CD008986, 2016. PMID: 26895968. DOI: 10.1002/14651858.CD008986.pub3

82 Beers MH, Ouslander JG, Rollingher I, Reuben DB, Brooks J and Beck JC: Explicit criteria for determining inappropriate medication use in nursing home residents. UCLA Division of Geriatric Medicine. Arch Intern Med 151(9): 1825-1832, 1991. PMID: 1888249.

83 By the American Geriatrics Society 2015 Beers Criteria Update Expert Panel: American Geriatrics Society 2015 Updated Beers criteria for potentially inappropriate medication use in older adults. J Am Geriatr Soc 63(11): 2227-2246, 2015. PMID: 26446832. DOI: $10.1111 /$ jgs. 13702

84 O'Connor MN, Gallagher P and O'Mahony D: Inappropriate prescribing: criteria, detection and prevention. Drugs Aging 29(6): 437-452, 2012. PMID: 22642779. DOI: 10.2165/11632 610-000000000-00000

85 Marriott J and Stehlik P: A critical analysis of the methods used to develop explicit clinical criteria for use in older people. Age Ageing 41(4): 441-450, 2012. PMID: 22711452. DOI: 10.1093/ageing/afs064

86 Hill-Taylor B, Sketris I, Hayden J, Byrne S, O’Sullivan D and Christie R: Application of the STOPP/START criteria: a systematic review of the prevalence of potentially inappropriate prescribing in older adults, and evidence of clinical, humanistic and economic impact. J Clin Pharm Ther 38(5): 360-372, 2013. PMID: 23550814. DOI: $10.1111 /$ jcpt.12059

87 Hohl CM, Dankoff J, Colacone A and Afilalo M: Polypharmacy, adverse drug-related events, and potential 
adverse drug interactions in elderly patients presenting to an emergency department. Ann Emerg Med 38(6): 666-671, 2001. PMID: 11719747. DOI: 10.1067/mem.2001.119456

88 Wolfe D, Yazdi F, Kanji S, Burry L, Beck A, Butler C, Esmaeilisaraji L, Hamel C, Hersi M, Skidmore B, Moher D and Hutton B: Incidence, causes, and consequences of preventable adverse drug reactions occurring in inpatients: A systematic review of systematic reviews. PLoS One 13(10): e0205426, 2018. PMID: 30308067. DOI: 10.1371/journal.pone.0205426

89 Lapatto-Reiniluoto O, Patinen L, Niemi M, Backman JT and Neuvonen PJ: Drug-related inadvertent deaths in a university hospital - a declining trend. Basic Clin Pharmacol Toxicol 117(6): 421-426, 2015. PMID: 26111726. DOI: 10.1111/bcpt.12435

90 Alhawassi TM, Krass I, Bajorek BV and Pont LG: A systematic review of the prevalence and risk factors for adverse drug reactions in the elderly in the acute care setting. Clin Interv Aging 9: 20792086, 2014. PMID: 25489239. DOI: $10.2147 /$ CIA.S71178

91 Ferner RE, Easton C and Cox AR: Deaths from medicines: a systematic analysis of coroners' reports to prevent future deaths. Drug Saf 41(1): 103-110, 2018. PMID: 28808959. DOI: 10.1007/s40264-017-0588-0

92 Beardon PH, McGilchrist MM, McKendrick AD, McDevitt DG and MacDonald TM: Primary non-compliance with prescribed medication in primary care. BMJ 307(6908): 846-848, 1993. PMID: 8401129. DOI: 10.1136/bmj.307.6908.846

93 Gardner TL, Dovey SM, Tilyard MW and Gurr E: Differences between prescribed and dispensed medications. N Z Med J 109(1017): 69-72, 1996. PMID: 8606821.

94 Food and Drug Administration: Guidance for Industry and Investigators: Safety Reporting Requirements for INDs and BA/BE Studies, pp 1-29, 2012. Available at: https://www.fda.gov/ files/drugs/published/Safety-Reporting-Requirements-for-INDs$\% 28$ Investigational-New-Drug-Applications\%29-and-BA-BE$\%$ 28Bioavailability-Bioequivalence\%29-Studies.pdf [Last accessed on February 12, 2022]

95 European Medicines Agency: Guideline on good pharmacovigilance practices (GVP) Annex I - Definitions (Rev 4), 2017. Available at: https://www.ema.europa.eu/en/documents/scientificguideline/guideline-good-pharmacovigilance-practices-annex-idefinitions-rev-4_en.pdf [Last accessed on February 12, 2022]

96 World Health Organization: The importance of pharmacovigilance. World Health Organization, 2002. Available at: https://apps. who.int/iris/bitstream/handle/10665/42493/a75646.pdf?sequence=1 \&isAllowed=y [Last accessed on February 12, 2022]

97 van der Hooft CS, Sturkenboom MC, van Grootheest K, Kingma $\mathrm{HJ}$ and Stricker $\mathrm{BH}$ : Adverse drug reaction-related hospitalisations: a nationwide study in The Netherlands. Drug Saf 29(2): 161-168, 2006. PMID: 16454543. DOI: $10.2165 /$ 00002018-200629020-00006

98 Bates DW, Evans RS, Murff H, Stetson PD, Pizziferri L and Hripcsak G: Detecting adverse events using information technology. J Am Med Inform Assoc 10(2): 115-128, 2003. PMID: 12595401. DOI: 10.1197/jamia.m1074

99 Sweis D and Wong IC: A survey on factors that could affect adverse drug reaction reporting according to hospital pharmacists in Great Britain. Drug Saf 23(2): 165-172, 2000. PMID: 10945377. DOI: 10.2165/00002018-200023020-00006

100 Smith CC, Bennett PM, Pearce HM, Harrison PI, Reynolds DJ, Aronson JK and Grahame-Smith DG: Adverse drug reactions in a hospital general medical unit meriting notification to the
Committee on Safety of Medicines. Br J Clin Pharmacol 42(4): 423-429, 1996. PMID: 8904613. DOI: 10.1046/j.13652125.1996.04376.x

101 Alvarez-Requejo A, Carvajal A, Bégaud B, Moride Y, Vega T and Arias LH: Under-reporting of adverse drug reactions. Estimate based on a spontaneous reporting scheme and a sentinel system. Eur J Clin Pharmacol 54(6): 483-488, 1998. PMID: 9776440 . DOI: $10.1007 / \mathrm{s} 002280050498$

102 Hazell L and Shakir SA: Under-reporting of adverse drug reactions : a systematic review. Drug Saf 29(5): 385-396, 2006. PMID: 16689555. DOI: 10.2165/00002018-200629050-00003

103 Abbas A, Green C and Mullen R: Attitudes of Non-medical Nurse Prescribers towards Reporting Adverse Drug Reactions via the Yellow Card Scheme - an Exploratory Study, 2017. Available at: https://www.ukmi.nhs.uk/filestore/ukmiamt/2018-AAAttitudes $\% 20$ of $\% 20$ Non-medical $\% 20$ Nurse $\% 20$ Prescribers.pdf [Last accessed on February 12, 2022]

104 Medicines and Healthcare products Regulatory Agency: Drug Safety Update volume 12, issue 10, 2019. Available at: https://www.gov.uk/drug-safety-update/yellow-card-please-helpto-reverse-the-decline-in-reporting-of-suspected-adverse-drugreactions [Last accessed on November 29, 2021]

105 Bégaud B, Martin K, Haramburu F and Moore N: Rates of spontaneous reporting of adverse drug reactions in France. JAMA 288(13): 1588, 2002. PMID: 12350188. DOI: 10.1001/ jama.288.13.1588

106 European Medicines Agency: Guideline on good pharmacovigilance practices (GVP) Module IX - Signal management (Rev 1). European Medicines Agency London, 2017. Available at: https://www.ema.europa.eu/en/documents/scientific-guideline/ guideline-good-pharmacovigilance-practices-gvp-module-ix-signalmanagement-rev-1_en.pdf [Last accessed on February 12, 2022]

107 Wise J: GPs are urged to report adverse drug reactions after a 37\% slump over nine years. BMJ 346: f690, 2013. PMID: 23377613. DOI: $10.1136 /$ bmj.f690

108 de Vries ST, Wong L, Sutcliffe A, Houÿez F, Ruiz CL, Mol PG and IMI Web-RADR Work Package 3b Consortium: Factors influencing the use of a mobile app for reporting adverse drug reactions and receiving safety information: a qualitative study. Drug Saf 40(5): 443-455, 2017. PMID: 28035492. DOI: 10.1007/s40264-016-0494-x

109 Coleman JJ and Pontefract SK: Adverse drug reactions. Clin Med (Lond) 16(5): 481-485, 2016. PMID: 27697815. DOI: 10.7861/clinmedicine.16-5-481

110 Scott HD, Thacher-Renshaw A, Rosenbaum SE, Waters WJ Jr, Green M, Andrews LG and Faich GA: Physician reporting of adverse drug reactions. Results of the Rhode Island Adverse Drug Reaction Reporting Project. JAMA 263(13): 1785-1788, 1990. PMID: 2313850.

111 Beninger P: Pharmacovigilance: An Overview. Clin Ther 40(12): 1991-2004, 2018. PMID: 30126707. DOI: 10.1016/ j.clinthera.2018.07.012

112 Stewart D, MacLure K, Paudyal V, Hughes C, Courtenay M and McLay J: Non-medical prescribers and pharmacovigilance: participation, competence and future needs. Int J Clin Pharm 35(2): 268-274, 2013. PMID: 23277419. DOI: 10.1007/s11096012-9739-7

113 Biagi C, Montanaro N, Buccellato E, Roberto G, Vaccheri A and Motola D: Underreporting in pharmacovigilance: an intervention for Italian GPs (Emilia-Romagna region). Eur J 
Clin Pharmacol 69(2): 237-244, 2013. PMID: 22706618. DOI: 10.1007/s00228-012-1321-7

114 Cox AR, Anton C, McDowell SE, Marriott JF and Ferner RE: Correlates of spontaneous reporting of adverse drug reactions within primary care: the paradox of low prescribers who are high reporters. Br J Clin Pharmacol 69(5): 529-534, 2010. PMID: 20573089. DOI: 10.1111/j.1365-2125.2010.03637.x

115 Khalili H, Mohebbi N, Hendoiee N, Keshtkar AA and DashtiKhavidaki S: Improvement of knowledge, attitude and perception of healthcare workers about ADR, a pre- and postclinical pharmacists' interventional study. BMJ Open 2: e000367, 2012. PMID: 22246555. DOI: 10.1136/bmjopen2011-000367

116 Bhagavathula AS, Elnour AA, Jamshed SQ and Shehab A: Health professionals' knowledge, attitudes and practices about pharmacovigilance in India: a systematic review and metaanalysis. PLoS One 11(3): e0152221, 2016. PMID: 27010447. DOI: 10.1371 journal.pone.0152221

117 Vigneshwaran E, Harichandana V, Sadiq M, Alavudeen S, Khan $\mathrm{N}$ and Ahmed $\mathrm{T}$ : Knowledge, attitude and practice of community pharmacists towards adverse drug reactions reporting. Journal of Young Pharmacists 12(1): 75-80, 2020. DOI: $10.5530 /$ jyp.2020.12.15

118 Prakasam A, Nidamanuri A and Kumar S: Knowledge, perception and practice of pharmacovigilance among community pharmacists in South India. Pharm Pract (Granada) 10(4): 222-226, 2012. PMID: 24155840. DOI: $10.4321 / \mathrm{s} 1886-$ 36552012000400006

119 Khan TM: Community pharmacists' knowledge and perceptions about adverse drug reactions and barriers towards their reporting in Eastern region, Alahsa, Saudi Arabia. Ther Adv Drug Saf 4(2): 45-51, 2013. PMID: 25083250. DOI: $10.1177 / 2042098612474292$

120 van Grootheest K, Olsson S, Couper M and de Jong-van den Berg L: Pharmacists' role in reporting adverse drug reactions in an international perspective. Pharmacoepidemiol Drug Saf 13(7): 457-464, 2004. PMID: 15269929. DOI: 10.1002/pds.897

121 Lee A, Bateman DN, Edwards C, Smith JM and Rawlins MD: Reporting of adverse drug reactions by hospital pharmacists: pilot scheme. BMJ 315(7107): 519, 1997. PMID: 9329307. DOI: $10.1136 / \mathrm{bmj} .315 .7107 .519$

122 Ahmad SR, Freiman JP, Graham DJ and Nelson RC: Quality of adverse drug experience reports submitted by pharmacists and physicians to the FDA. Pharmacoepidemiol Drug Saf 5(1): 17, 1996. PMID: 15088271. DOI: 10.1002/(SICI)10991557(199601)5:1<1::AID-PDS203>3.0.CO;2-T

123 van Grootheest AC, van Puijenbroek EP and de Jong-van den Berg LT: Contribution of pharmacists to the reporting of adverse drug reactions. Pharmacoepidemiol Drug Saf 11(3): 205-210, 2002. PMID: 12051119. DOI: 10.1002/pds.702

124 Green CF, Mottram DR, Rowe PH and Pirmohamed M: Attitudes and knowledge of hospital pharmacists to adverse drug reaction reporting. Br J Clin Pharmacol 51(1): 81-86, 2001. PMID: 11167664. DOI: 10.1046/j.1365-2125.2001.01306.x

125 Molokhia M, Tanna S and Bell D: Improving reporting of adverse drug reactions: Systematic review. Clin Epidemiol 1: 75-92, 2009. PMID: 20865089. DOI: 10.2147/clep.s4775

126 Reumerman M, Tichelaar J, Piersma B, Richir MC and van Agtmael MA: Urgent need to modernize pharmacovigilance education in healthcare curricula: review of the literature. Eur
J Clin Pharmacol 74(10): 1235-1248, 2018. PMID: 29926135. DOI: $10.1007 / \mathrm{s} 00228-018-2500-y$

127 van Eekeren R, Rolfes L, Koster AS, Magro L, Parthasarathi G, Al Ramimmy H, Schutte T, Tanaka D, van Puijenbroek E and Härmark L: What future healthcare professionals need to know about pharmacovigilance: Introduction of the WHO PV core curriculum for university teaching with focus on clinical aspects. Drug Saf 41(11): 1003-1011, 2018. PMID: 29949100. DOI: $10.1007 / \mathrm{s} 40264-018-0681-\mathrm{z}$

128 George C, Nathanson V, Seddon C, Jayesinghe N and Jackson G: Reporting adverse drug reactions a guide for healthcare professionals, 2006. Available at: https://www.isoponline.org/wpcontent/uploads/2015/01/BMAreport.pdf [Last accessed on February 12, 2022]

129 Dubrall D, Schmid M, Alešik E, Paeschke N, Stingl J and Sachs B: Frequent adverse drug reactions, and medication groups under suspicion. Dtsch Arztebl Int 115(23): 393-400, 2018. PMID: 29960607. DOI: 10.3238/arztebl.2018.0393

130 European Medicines Agency: Medicines under additional monitoring. Available at: https://www.ema.europa.eu/en/humanregulatory/post-authorisation/pharmacovigilance/medicines-underadditional-monitoring [Last accessed on December 11, 2020]

131 Edwards IR and Aronson JK: Adverse drug reactions: definitions, diagnosis, and management. Lancet 356(9237): 1255-1259, 2000. PMID: 11072960. DOI: 10.1016/S01406736(00)02799-9

132 Palleria C, Leporini C, Chimirri S, Marrazzo G, Sacchetta S, Bruno L, Lista RM, Staltari O, Scuteri A, Scicchitano F and Russo E: Limitations and obstacles of the spontaneous adverse drugs reactions reporting: Two "challenging" case reports. J Pharmacol Pharmacother 4(Suppl 1): S66-S72, 2013. PMID: 24347986. DOI: 10.4103/0976-500X.120955

133 Rolfes L, van Hunsel F, Wilkes S, van Grootheest K and van Puijenbroek E: Adverse drug reaction reports of patients and healthcare professionals-differences in reported information. Pharmacoepidemiol Drug Saf 24(2): 152-158, 2015. PMID: 25079444. DOI: $10.1002 /$ pds.3687

134 van Grootheest K, de Graaf L and de Jong-van den Berg LT: Consumer adverse drug reaction reporting: a new step in pharmacovigilance? Drug Saf 26(4): 211-217, 2003. PMID: 12608885. DOI: 10.2165/00002018-200326040-00001

135 Foster JM, van der Molen T and de Jong-van den Berg L: Patient-reporting of side effects may provide an important source of information in clinical practice. Eur J Clin Pharmacol 63(10): 979-80; author reply 981, 2007. PMID: 17618426. DOI: $10.1007 / \mathrm{s} 00228-007-0339-8$

136 de Langen J, van Hunsel F, Passier A, de Jong-van den Berg L and van Grootheest $\mathrm{K}$ : Adverse drug reaction reporting by patients in the Netherlands: three years of experience. Drug Saf 31(6): 515-524, 2008. PMID: 18484785. DOI: 10.2165/ 00002018-200831060-00006

137 Jarernsiripornkul N, Krska J, Richards RM and Capps PA: Patient reporting of adverse drug reactions: useful information for pain management? Eur J Pain 7(3): 219-224, 2003. PMID: 12725844. DOI: 10.1016/S1090-3801(02)00114-3

138 Basch E: The missing voice of patients in drug-safety reporting. N Engl J Med 362(10): 865-869, 2010. PMID: 20220181. DOI: 10.1056/NEJMp0911494

139 Avery AJ, Anderson C, Bond CM, Fortnum H, Gifford A, Hannaford PC, Hazell L, Krska J, Lee AJ, McLernon DJ, 
Murphy E, Shakir S and Watson MC: Evaluation of patient reporting of adverse drug reactions to the UK 'Yellow Card Scheme': literature review, descriptive and qualitative analyses, and questionnaire surveys. Health Technol Assess 15(20): 1234, iii-iv, 2011. PMID: 21545758. DOI: 10.3310/hta15200

140 van Hunsel F, Passier A and van Grootheest K: Comparing patients' and healthcare professionals' ADR reports after media attention: the broadcast of a Dutch television programme about the benefits and risks of statins as an example. Br J Clin Pharmacol 67(5): 558-564, 2009. PMID: 19552751. DOI: 10.1111/j.1365-2125.2009.03400.x

141 Vilhelmsson A, Svensson T, Meeuwisse A and Carlsten A: Experiences from consumer reports on psychiatric adverse drug reactions with antidepressant medication: a qualitative study of reports to a consumer association. BMC Pharmacol Toxicol 13: 19, 2012. PMID: 23259410. DOI: 10.1186/2050-6511-13-19

142 McLernon DJ, Bond CM, Hannaford PC, Watson MC, Lee AJ, Hazell L, Avery A and Yellow Card Collaboration: Adverse drug reaction reporting in the UK: a retrospective observational comparison of yellow card reports submitted by patients and healthcare professionals. Drug Saf 33(9): 775-788, 2010. PMID: 20701410. DOI: 10.2165/11536510-000000000-00000

143 van Hunsel FPAM: The contribution of direct patient reporting to pharmacovigilance, 2011. Available at: https:// www.lareb.nl/media/3026/2011_4_thesis_patient_reporting.pdf [Last accessed on February 12, 2022]

144 Leone R, Moretti U, D’Incau P, Conforti A, Magro L, Lora R and Velo G: Effect of pharmacist involvement on patient reporting of adverse drug reactions: first Italian study. Drug Saf 36(4): 267-276, 2013. PMID: 23475583. DOI: 10.1007/s40264013-0028-8

145 Clothier HJ, Selvaraj G, Easton ML, Lewis G, Crawford NW and Buttery JP: Consumer reporting of adverse events following immunization. Hum Vaccin Immunother 10(12): 3726-3730, 2014. PMID: 25483686. DOI: 10.4161/hv.34369
146 van Grootheest AC, Passier JL and van Puijenbroek EP: [Direct reporting of side effects by the patient: favourable experience in the first year]. Ned Tijdschr Geneeskd 149(10): 529-533, 2005. PMID: 15782689.

147 Durrieu G, Palmaro A, Pourcel L, Caillet C, Faucher A, Jacquet A, Ouaret S, Perault-Pochat MC, Kreft-Jais C, Castot A, Lapeyre-Mestre M, Montastruc JL and French Network of Pharmacovigilance Centres: First French experience of ADR reporting by patients after a mass immunization campaign with Influenza A (H1N1) pandemic vaccines: a comparison of reports submitted by patients and healthcare professionals. Drug Saf 35(10): 845-854, 2012. PMID: 22967189. DOI: 10.1007/BF03261980

148 Aagaard L, Nielsen LH and Hansen EH: Consumer reporting of adverse drug reactions: a retrospective analysis of the Danish adverse drug reaction database from 2004 to 2006. Drug Saf 32(11): 1067-1074, 2009. PMID: 19810778. DOI: 10.2165/ 11316680-000000000-00000

149 Giles S: Yellow Card Scheme reaches 50. Prescriber 26(18): 66, 2021. DOI: $10.1002 / \mathrm{psb} .1383$

150 Egberts TC, Smulders M, de Koning FH, Meyboom RH and Leufkens HG: Can adverse drug reactions be detected earlier? A comparison of reports by patients and professionals. BMJ 313(7056): 530-531, 1996. PMID: 8789980. DOI: 10.1136/ bmj.313.7056.530

151 Mitchell AS, Henry DA, Sanson-Fisher R and O'Connell DL: Patients as a direct source of information on adverse drug reactions. BMJ 297(6653): 891-893, 1988. PMID: 3140967. DOI: $10.1136 / \mathrm{bmj} .297 .6653 .891$

Received December 17, 2021

Revised January 29, 2022

Accepted February 14, 2022 